OPEN ACCESS

Edited by:

Roberto Silva,

Universidade de São Paulo, Brazi

Reviewed by:

Baskar Gurunathan,

St. Joseph's College of Engineering,

India

Ching Man Wai,

Michigan State University,

United States

*Correspondence:

Robert Neil Gerard Miller

robertmiller@unb.br

Specialty section:

This article was submitted to

Bioenergy and Biofuels,

a section of the journal

Frontiers in Bioengineering and

Biotechnology

Received: 06 July 2018

Accepted: 20 August 2018

Published: 18 September 2018

Citation:

Midorikawa GEO, Correa CL, Noronha EF, Filho EXF, Togawa RC,

Costa MMdC, Silva-Junior $O B$,

Grynberg P and Miller RNG (2018)

Analysis of the Transcriptome in Aspergillus tamarii During Enzymatic Degradation of Sugarcane Bagasse.

Front. Bioeng. Biotechnol. 6:123.

doi: 10.3389/fbioe.2018.00123

\section{Analysis of the Transcriptome in Aspergillus tamarii During Enzymatic Degradation of Sugarcane Bagasse}

\author{
Glaucia Emy Okida Midorikawa ${ }^{1}$, Camila Louly Correa ${ }^{1}$, Eliane Ferreira Noronha ${ }^{1}$, \\ Edivaldo Ximenes Ferreira Filho ${ }^{1}$, Roberto Coiti Togawa ${ }^{2}$, Marcos Mota do Carmo Costa ${ }^{2}$, \\ Orzenil Bonfim Silva-Junior ${ }^{2}$, Priscila Grynberg ${ }^{2}$ and Robert Neil Gerard Miller ${ }^{1 *}$
}

${ }^{1}$ Departamento de Biologia Celular, Universidade de Brasilia, Brasilia, Brazil, ${ }^{2}$ Embrapa Recursos Genéticos e Biotecnologia, Parque Estação Biológica, Brasília, Brazil

The production of bioethanol from non-food agricultural residues represents an alternative energy source to fossil fuels for incorporation into the world's economy. Within the context of bioconversion of plant biomass into renewable energy using improved enzymatic cocktails, Illumina RNA-seq transcriptome profiling was conducted on a strain of Aspergillus tamarii, efficient in biomass polysaccharide degradation, in order to identify genes encoding proteins involved in plant biomass saccharification. Enzyme production and gene expression was compared following growth in liquid and semi-solid culture with steam-exploded sugarcane bagasse (SB) $(1 \% \mathrm{~W} / \mathrm{V})$ and glucose $(1 \% \mathrm{~W} / \mathrm{V})$ employed as contrasting sole carbon sources. Enzyme production following growth in liquid minimum medium supplemented with SB resulted in 0.626 and $0.711 \mathrm{UI} \cdot \mathrm{mL}^{-1}$ xylanases after 24 and $48 \mathrm{~h}$ incubation, respectively. Transcriptome profiling revealed expression of over 7120 genes, with groups of genes modulated according to solid or semi-solid culture, as well as according to carbon source. Gene ontology analysis of genes expressed following SB hydrolysis revealed enrichment in xyloglucan metabolic process and xylan, pectin and glucan catabolic process, indicating up-regulation of genes involved in xylanase secretion. According to carbohydrate-active enzyme (CAZy) classification, 209 CAZyme-encoding genes were identified with significant differential expression on liquid or semi-solid SB, in comparison to equivalent growth on glucose as carbon source. Up-regulated CAZyme-encoding genes related to cellulases (CelA, CelB, CelC, CelD) and hemicellulases (XynG1, XynG2, XynF1, XylA, AxeA, arabinofuranosidase) showed up to a 10-fold log2FoldChange in expression levels. Five genes from the AA9 (GH61) family, related to lytic polysaccharide monooxygenase (LPMO), were also identified with significant expression up-regulation. The transcription factor gene $\mathrm{XInR}$, involved in induction of hemicellulases, showed up-regulation on liquid and semi-solid SB culture. Similarly, the gene ClrA, responsible for regulation of cellulases, showed increased expression on liquid SB culture. Over 150 potential transporter genes were also identified with increased expression on liquid and semi-solid SB culture. This first comprehensive 
analysis of the transcriptome of $A$. tamarii contributes to our understanding of genes and regulatory systems involved in cellulose and hemicellulose degradation in this fungus, offering potential for application in improved enzymatic cocktail development for plant biomass degradation in biorefinery applications.

Keywords: Aspergillus tamarii, transcriptome, carbohydrate-active enzymes, XInR, CIrA, sugar transporters, lignocellulose, bioethanol

\section{INTRODUCTION}

The production of renewable energy is one of the greatest challenges of the twenty-first Century. Whilst dependency upon fossil fuels is associated with depleting oil reserves and greenhouse gas emissions, plant biomass, by contrast, with its' global abundancy, represents a sustainable and environmentally clean energy source (Goldemberg, 2007; Tan et al., 2016).

The production of bioethanol from non-food agricultural residues such as lignocellulosic trash, grasses and woods, is known as second-generation (2G) ethanol (Alvira et al., 2010), and is considered a promising alternative energy source to fossil fuels for incorporation into the world's economy. Brazil is currently one of the principal agricultural producers, as an important supplier of both food and industrial crops. Sugarcane is planted over an area of almost 9 million hectares, with an annual production of over 620 million tons (CONAB, 2018). Whilst around $45 \%$ of the crop production is employed for sugar extraction, the majority is used in the bioethanol industry, with estimates of production of 28 billion liters of anhydrous and hydrated ethanol for 2018/2019 (CONAB, 2018). Bioethanol production in Brazil is based almost exclusively on first-generation technologies, whereby the sucrose content of the plant is converted into ethanol. In this process, sugarcane bagasse will accumulate as an agricultural residue (Goldemberg, 2008). Whilst the burning of bagasse currently serves as an energy source in bioethanol mills, as this biomass represents approximately one-third of the energy content of the crop, the conversion of the lignocellulose component of the cell wall into fermentable hexose (glucose) and pentose (e.g., D-xylose and L-arabinose) sugars offers considerable potential for increased $2 \mathrm{G}$ ethanol production, potentially by up to $40 \%$ (Amorim et al., 2011). Two Brazilian cellulosic ethanol plants came into operation in 2014, with capacities planned for production of up to 1 billion liters of ethanol per year from bagasse (Silva et al., 2017).

For economically viable $2 \mathrm{G}$ ethanol production, complete hydrolysis, or saccharification, of plant biomass is required. Such plant material is composed mainly of polysaccharide crystalline microfibers of cellulose (40-50\%), followed in abundance by a matrix of various hemicelluloses and pectins (25-35\%), in addition to the polyaromatic lignin (15-20\%) (Lin and Tanaka, 2006; Ragauskas et al., 2006; Jordan et al., 2012; Guerriero et al., 2016). Efficient biorefinary-based conversion of this material is hampered due to the recalcitrance of lignocelluloses (Chundawat et al., 2011). In the case of sugarcane bagasse, lignocellulose sugars vary in terms of identity and branching, comprising residues of glucose $(60 \%)$, xylose $(13 \%)$, arabinose $(6 \%)$, mannose $(3 \%)$, galactose $(1,5 \%)$, and less than $1 \%$ fructose and rhamnose (Häkkinen et al., 2012).

As cellulases and hemicellulases remain costly, increasing the costs of $2 \mathrm{G}$ bioethanol production, a continued characterization of sources of such enzymes, together with an improved understanding of the mechanisms involved in enzyme secretion and enzyme efficiency are of fundamental importance for the biofuel industry. Hydrolytic enzymes appropriate for fermentation of available sugars in lignocelluloses are known to be secreted by a wide variety of bacteria and filamentous fungi, with the latter often producing not only a diverse array of extracellular lignocellulolitic enzymes, but also displaying efficiency in secretion of such enzymes in high quantities (Phitsuwan et al., 2013). For this reason, fungi are today the principal source of hydrolytic enzymes for this industrial application (Sims et al., 2010; Couturier et al., 2012).

Lignocellulolytic fungi typically produce extensive sets of carbohydrate-active enzymes (CAZymes) that correlate with their geographical origin habitat (Van Den Brink and De Vries, 2011). A number of ascomycete fungi, notably species members of the genera Trichoderma and Aspergillus, produce a range of cellulases and hemicellulases, which are today applied across numerous relevant industries for production of food, feed, paper, textiles and pharmaceuticals (Archer, 2000; de Souza et al., 2011). Whilst Aspergillus niger and Trichoderma reseei are currently employed in the production of commercial enzymatic cocktails for lignocellulosic biomass deconstruction (Singhania, 2011; Mohanram et al., 2013), the identification of additional sources of carbohydrate active enzymes will likely increase efficiency in the deconstruction of this biomass. As such, additional species have recently been screened as potential sources of cellulases, hemicellulases and accessory proteins for optimized industrial enzyme production (Brown et al., 2016; Cong et al., 2017; de Gouvêa et al., 2018).

The availability of whole genome sequences for fungi has improved understanding of fungal biodiversity with respect to plant cell wall degradation. Aspergillus nidulans, considered the model species of the genus given its' well-elucidated sexual cycle, possesses a genome sequence of $30.06 \mathrm{MB}$, with 9396 predicted genes (Galagan et al., 2005). Other characterized Aspergillus species of importance for the food, textile, pulp and paper industries, and potentially in $2 \mathrm{G}$ ethanol production, include $A$. oryzae and A. niger. A. oryzae has a total genome size of $37.12 \mathrm{MB}$, with 12336 predicted genes (Machida et al., 2005). Similarly, A. niger possesses a genome of $37.2 \mathrm{MB}$, with 14600 predicted genes (Pel et al., 2007). Comparison of gene sequences against 
the Carbohydrate-Active Enzymes Database (http://www.cazy. org/) (Cantarel et al., 2009) has revealed 186 genes related to polysaccharide hydrolysis in A. nidulans, 217 in A. oryzae and 171 in $A$. niger (Delmas et al., 2012).

In addition to gene discovery, the annotated genome sequences for these species serve as resources for analysis of the transcriptome in additional Aspergillus species without available genome sequences. Such analysis of transcriptional regulation of genes encoding hydrolytic enzymes in Aspergillus has been studied in relation to growth on different sugar carbon sources (Andersen et al., 2008; Jørgensen et al., 2009; Salazar et al., 2009). In relation to fermentation of sugarcane bagasse, microarray analysis provided information on gene expression modulation in A. niger (Guillemette et al., 2007; de Souza et al., 2011), with cellulases, hemicellulases and transporters identified with increased expression during growth on sugarcane bagasse in comparison to fructose. Subsequent RNAseq analysis of the A. niger transcriptome, following growth on wheat straw compared to simple sugars, revealed a CAZy gene representation change from $3 \%$ of total mRNA on $1 \%$ glucose to $19 \%$ on wheat straw, representing numerous enzymes from the classes of Glycoside Hydrolases (GH), Carbohydrate Esterases (CE), and Polysaccharide Lyases (PL) (Delmas et al., 2012). Further RNAseq-based analysis of gene expression in Aspergillus species following growth on sugarcane bagasse as carbon source has also revealed important information regarding regulatory mechanisms and genes encoding plant cell wall degrading enzymes, accessory proteins and transporters (Pullan et al., 2014; Brown et al., 2016; Borin et al., 2017; Cong et al., 2017; de Gouvêa et al., 2018).

The continued characterization of hydrolases, accessory proteins and the regulation of their expression in Aspergillus species that display efficiency in degradation of lignocellulose will further our understanding of their roles in saccharification. Given the importance of Aspergillus tamarii as an efficient producer of enzymes such as xylanases (El-Gindy et al., 2015; Monclaro et al., 2016), we utilized an Illumina RNA-seq approach to analyze the transcriptome in this fungus following semisolid and liquid cultivation on steam-exploded bagasse (SB) compared gene expression following growth on glucose $(G)$. Genes encoding cellulases and hemicellulases, transcription factors and transporters are characterized in relation to their differential expression following fungal growth on each carbon source. Data will benefit the development of improved fungal strains with increased ability to deconstruct lignocellulose and generate value-added bioproducts.

\section{MATERIALS AND METHODS Strain and Culture Conditions}

A stock culture of a strain of A. tamarii, code BLU37, was provided by the fungal culture collection at the Enzymology Laboratory, University of Brasilia, Brazil (genetic heritage number $010237 / 2015-1$ ). The strain was originally isolated into pure culture from natural composting cotton textile waste material in the Vale do Itajaí, Santa Catarina, Brazil (Siqueira et al., 2009) and maintained in the culture collection at $-80^{\circ} \mathrm{C}$ in $50 \%$ glycerol.

Species identity reconfirmation was conducted by sequence analysis of the nuclear ribosomal DNA (rDNA) ITS1-5.8SITS2 region, together with specific regions of the $\beta$-tubulin and calmodulin genes. Genomic DNA was extracted according to Raeder and Broda (1985) from a 3 day old liquid culture in Czapek Yeast Extract medium (CYA) (Pitt and Hocking, 2009) incubated on an orbital shaker at $28^{\circ} \mathrm{C}$. Each PCR reaction contained $10 \mathrm{ng}$ genomic DNA, 2,5 $\mathrm{mmol}^{-1}$ of each primer, $1 \mathrm{mmol}^{-1}$ dNTPs, $4 \mathrm{mmol}^{-1} \mathrm{MgCl}_{2}, 1 \mathrm{U}$ of Taq Platinum ${ }^{\circledR}$ polymerase (Invitrogen) and $1 \mathrm{x}$ Taq Platinum ${ }^{\circledR}$ polymerase buffer (Invitrogen). Ribosomal DNA ITS regions were amplified using primers ITS5 and ITS4 (White et al., 1990), a $\beta$-tubulin gene region with primers $\mathrm{Bt}_{2} \mathrm{a}$ and $\mathrm{Bt}_{2} \mathrm{~b}$ (Glass and Donaldson, 1995), and a calmodulin gene region amplified with primers Cmd5 and Cmd6 (Hong et al., 2006). PCR cycling was performed with the following programs: initial denaturation at $94^{\circ} \mathrm{C}$ for $4 \mathrm{~min}, 30$ cycles of denaturation at $94^{\circ} \mathrm{C}$ for $1 \mathrm{~min}$, primer annealing for $1 \mathrm{~min}$, at $50^{\circ} \mathrm{C}$ for primers ITS5 and ITS4, and at $60^{\circ} \mathrm{C}$ for primers $\mathrm{Bt} 2 \mathrm{a}, \mathrm{Bt} 2 \mathrm{~b}, \mathrm{Cmd} 5$ and $\mathrm{Cmd} 6$, extension at $72^{\circ} \mathrm{C}$ for $1 \mathrm{~min}$, and a final extension period at $72^{\circ} \mathrm{C}$ for $5 \mathrm{~min}$. PCR products were purified using ExoSAP-IT ${ }^{\circledR}$ (USB, Cleveland, Ohio, USA) and sequenced using Big Dye ${ }^{\circledR}$ Terminator v3.1 Cycle Sequencing chemistry (Applied Biosystems, Foster City, CA, USA) on an ABI 3700 DNA sequencer (Applied Biosystems, Foster City, CA, USA). For molecular identification, sequences were compared against the nucleotide database NCBI using the BLASTn algorithm (Altschul et al., 1990). Ribosomal DNA ITS, $\beta$-tubulin and calmodulin gene sequences were deposited in GenBank under accession numbers MH540359, MH544272 and MH544273, respectively.

For analysis of gene expression in BLU37 following exposure to $\mathrm{SB}$ or glucose as carbon source, the strain was grown in either liquid or semi-solid minimal medium $\left(\mathrm{KH}_{2} \mathrm{PO}_{4} 7 \mathrm{~g}\right.$; $\mathrm{K}_{2} \mathrm{HPO}_{4} 2 \mathrm{~g} ; \mathrm{MgSO}_{4} 0.4 \mathrm{~g} ;\left(\mathrm{NH}_{4}\right)_{2} \mathrm{SO}_{4} 1.6 \mathrm{~g}$, pH 7.0, per liter of distilled water), containing $\mathrm{SB}(1 \% w / v)$ or glucose $(1 \% w / v)$ (Sigma Aldrich) as exclusive carbon source. In order to guarantee elimination of reducing sugars, prior to fungal inoculation, SB was repeatedly washed with deionized water until reducing sugars were no longer detectable by the colorimetric dinitrosalicylic acid (DNS) assay (Miller, 1959). Liquid cultures were grown in $100 \mathrm{~mL}$ of media in Erlenmeyer flasks, whilst semi-solid cultures were grown on petri plates with media supplemented with agar $\left(15 \mathrm{~g} \mathrm{~L}^{-1}\right)$. Fungal spores at a concentration of $1 \times 10^{8}$ conidiospores $\mathrm{mL}^{-1}$ were used as inocula, with cultures then incubated at $28^{\circ} \mathrm{C}$ and $150 \mathrm{rpm}$ for 36 and $48 \mathrm{~h}$. Fungal cultures were arranged in a randomized block design, with three replicates for each treatment and time point. Growth treatments were labeled as follows: liquid medium, SB carbon source, $36 \mathrm{~h}$ incubation (LB36); liquid medium, glucose carbon source, $36 \mathrm{~h}$ incubation (LG36); liquid medium, SB carbon source, $48 \mathrm{~h}$ incubation (LB48); liquid medium, glucose carbon source, $48 \mathrm{~h}$ incubation (LG48); semi-solid medium SB carbon source, $36 \mathrm{~h}$ incubation (SB36); semi-solid medium, glucose carbon source, $36 \mathrm{~h}$ incubation (SG36); semi-solid medium, SB carbon source, $48 \mathrm{~h}$ incubation 
(SB48); semi-solid medium, glucose carbon source, $48 \mathrm{~h}$ incubation (SG48).

\section{Analysis of Enzymatic Activities}

Analysis of hydrolytic enzyme secretion was conducted following fungal growth in the liquid minimal medium with SB (1\% $w / v)$ or glucose $(1 \% w / v)$ as carbon source. Enzyme activities were evaluated over a 10 day period at $24 \mathrm{~h}$ intervals. Xylanase, CMCase, pectinase and FPase assays were determined using the DNS assay at $\mathrm{pH}$ 5.0. Each assay comprised $10 \mu \mathrm{l}$ of the fungal secretome, together with xylan $(1 \% w / v)$, carboxy methylcellulose $(1 \% w / v)$, or pectin $(1 \% w / v)$ as substrate. An assay for FPase activity, as a measurement of total cellulases, was conducted according to Ghose (1987). All assays were conducted with at least three replicates. Quantification of reduced sugars from the assays was conducted using a spectrophotometer at an absorbance of $540 \mathrm{~nm}$ (Spectra Max), calibrated using standard curves of glucose, xylose and galacturonic acid. Absorbance values for each assay were calculated in international units (UI), where 1 UI was defined as the amount of enzyme necessary to release $1 \mu \mathrm{mol}$ of reducing sugars per minute per liter by hydrolysis of each crude substrate.

\section{Vizualization of Fungal Colonization of SB by Scanning Electron Microscopy}

Following 36 and $48 \mathrm{~h}$ mycelial growth, liquid minimum medium culture supplemented with SB was filtered with Whatman ${ }^{\circledR}$ filter paper $\mathrm{n}^{\circ} 1$ and washed with Karnovsky buffer (0.05M; pH 7.2). Samples were fixed for $4 \mathrm{~h}$ in a fresh solution of $0.05 \mathrm{M}$ cacodylate buffer at $\mathrm{pH}$ 7.4. Following dehydration with acetone, samples were postfixed for $1 \mathrm{~h}$ using $1 \%$ osmium tetroxide. Samples were washed in liquid $\mathrm{CO}_{2}$ at $4^{\circ} \mathrm{C}$, dried in a critical point drier (Emitech K850, Kent, UK), mounted on copper stubs then sputter coated with $20 \mathrm{~nm}$ gold particles. Prepared samples were observed under scanning electron microscopy using a Zeiss DSM 962 scanning electron microscope.

\section{Total RNA Extraction and Illumina RNA-seq}

Following 36 and $48 \mathrm{~h}$ incubation, total RNA was extracted from each culture according to a standard phenol/chloroform method (Brasileiro et al., 2015). Mycelia from liquid media was collected by filtration with Whatman ${ }^{\circledR}$ filter paper $n^{\circ} 1$, whilst from semi-solid cultures mycelia from the surface of each agar plate was collected manually using a sterilized spatula. Extracted total RNA was quantified and integrity determined using an Agilent 2100 Bioanalyzer and RNA LabChip ${ }^{\circledR}$ kit system (Agilent Technologies, Santa Clara, CA, USA). Isolation of mRNA, cDNA library construction and Illumina RNA-seq were conducted by Eurofins MWG Operon (Louisville, KY, USA). All treatments from the replicate bioassays were paired-end sequenced $(2 \times 100$ bases) using TruSeq RNA Chemistry v3 on two flow cell channels of an Illumina Hiseq2000 system (Illumina Inc., San Diego CA, USA).

\section{Bioinformatics Analysis}

Read Mapping and Assembly

Quality was determined for sequence reads from each cDNA library using ea-utils (Aronesty, 2011). For assignment of reads to gene models for the genus, high quality sequences (Fastq QC $>30$ ) were mapped against the reference annotated genome sequence for the phylogenetically related species $A$. oryzae, strain RIB40 (National Research Institute of Brewing Stock Culture and ATCC-42149 (Machida et al., 2005), publically available at DOGAN (http://www.bio.nite.go.jp/dogan/Top). Alignment and assembly were conducted using the programs TopHat (Trapnell et al., 2009) and Cufflinks (Trapnell et al., 2010).

\section{Analysis of Gene Expression Levels for Normalized Data}

Genes with statistically significant differential expression between the evaluated growth conditions were identified on the basis of comparisons of in silico data. Read counts aligned to each gene were determined using the Python script HTseq-count (Anders et al., 2015). Differences in gene expression levels between treatments were calculated using the DEGseq program (Wang et al., 2010a). Differentially expressed genes (DEGs) between evaluated treatments were considered to be significant if a $\log 2$ fold change (FC) was at least $\geq 2$-fold and at a probability level of $p \leq 0.01$.

\section{Gene Ontology and Analysis of Enrichment}

Using the program FUNC (Prüfer et al., 2007), a hypergeometric test enabled analysis of both over- and under-representation of DEGs according to gene function classification within gene ontology categories (GO). Redundancy in category terms was eliminated using the program REVIGO (http://revigo.irb.hr/).

\section{Carbohydrate-Active Enzymes}

Identification of genes encoding hydrolytic enzymes was conducted through alignment against the Carbohydrate-Active Enzymes (CAZymes) database (http://www.cazy.org/) (Cantarel et al., 2009), to enable classification of glycosyl hydrolases, glycosyltransfereases, carbohydrate-binding modules and carbohydrate esterases.

\section{Transcription Factors}

Transcription factors were identified following alignment of gene sequences against the Fungal Transcription Factor Database (FTFD) (http://ftfd.snu.ac.kr/index.php?a=view).

\section{Validation of RNAseq-Derived DEGs by RT-qPCR}

To validate DEGs identified on the basis of in silico transcriptome data, a RT-qPCR analysis was conducted according to MIQE guidelines (Bustin et al., 2009). All specific primers were designed with Primer Express ${ }^{\circledR}$ software (Applied Biosystems) and evaluated at OligoAnalyzer 3.1 - IDT (https://www. idtdna.com/calc/analyzer). All cDNA libraries were synthesized using the same RNA samples employed for RNAseq analysis. Three independent biological replicates were analyzed for each carbon source and time point treatment, with three technical 
replicates per amplification. Total RNA was treated with $2 \mathrm{U}$ of Amplification Grade DNase I (Invitrogen, Carlsbad, CA, USA) and cDNA was synthesized with Oligo(dT)20 primers (Invitrogen, Carlsbad, CA, USA) and SuperScript ${ }^{\circledR}$ II Reverse Transcriptase (Invitrogen, Carlsbad, CA, USA). PCR was carried on a Step One Plus Real Time PCR System (Applied Biosystems) using a Platinum ${ }^{\circledR}$ SYBR $^{\circledR}$ Green qPCR Super Mix-UDG w/ROX kit (Invitrogen, Carlsbad, CA, USA) according to the manufacturer's recommendations and $1 \mu \mathrm{L}$ of template cDNA. Thermocycling was performed with 40 cycles of denaturation at $95^{\circ} \mathrm{C}$ for $15 \mathrm{~s}$, followed by primer annealing and extension at $60^{\circ} \mathrm{C}$ for $30 \mathrm{~s}$. GAPDH (Wang et al., 2010b) and $\beta$-tubulin (Mckelvey and Murphy, 2010) were employed as stable reference genes. Cycle threshold $(\mathrm{Ct})$ values were determined using the program SDS 2.2.2 (Applied Biosystems, Foster City, USA), with specificity of PCR products for each primer set verified according to the Tm (dissociation) of the amplified products. Individual amplification efficiencies were calculated with the program LinRegPCR, version 2013.0, using a window-of-linearity. Gene expression values were calculated according to the 2- $\Delta \Delta \mathrm{CT}$ method (Livak and Schmittgen, 2001).

\section{RESULTS}

\section{Fungal Growth on Steam-Exploded Sugarcane Bagasse}

Scanning electron microscopy-based observation of liquid minimal medium culture supplemented with SB following inoculation with $A$. tamarii conidia revealed evidence for degradation of sugarcane bagasse after incubation with the fungus (Figure 1). Homogeneous SB parenchyma fragments prior to inoculation can be observed in Figure 1A, with mycelial growth and resultant disruption of the parenchyma surface clearly visible in Figures 1B,C, following 36 and $48 \mathrm{~h}$ fungal colonization.

\section{Evaluation of Enzyme Production}

In order to gain an understanding of the genes and pathways involved in xylanase and cellulase induction following exposure to $\mathrm{SB}$, analysis of enzyme secretion in A. tamarii BLU37 was firstly conducted over a 10 day period following growth on liquid minimal medium culture supplemented with SB, as well as on the same medium with a glucose carbon source as control (Figure 2). Xylanase activity was shown to rapidly increase during the first $24 \mathrm{~h}$ on SB $(0.626 \pm 0.001)$, in contrast to growth on glucose $(0.000 \pm 0.004)$, with activity remaining relatively constant over the 10 day period. The activities of CMCases, pectinases and FPases at $24 \mathrm{~h}$ on SB were inferior in comparison to xylanases $(0.096 \pm 0.002,0.039 \pm 0.004$, and $0.159 \pm 0.037$, respectively) although they were clearly induced by SB when compared to values for these enzymes following growth in glucose $(0.000 \pm$ $0.002,0.006 \pm 0.007$, and $0.000 \pm 0.088$, respectively). Again, the expression of these enzymes remained relatively constant throughout the 10 day evaluation time course. Given the kinetics of xylanase production on SB, together with evidence for carbon catabolic repression during the first $48 \mathrm{~h}$ of growth on glucose, 36 and $48 \mathrm{~h}$ were selected as time points for analysis of the

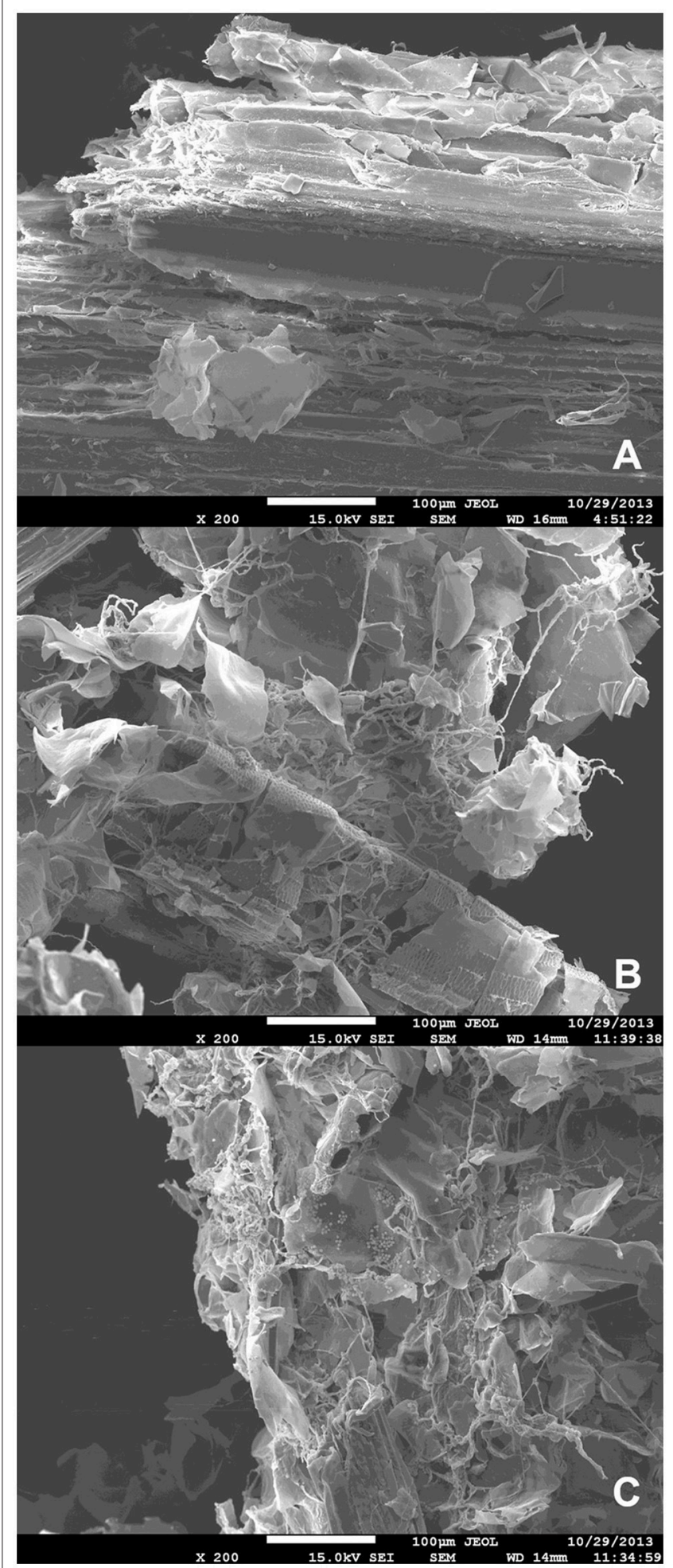

FIGURE 1 | Scanning electron microscopy images of (A) non-inoculated steam-exploded sugarcane bagasse parenchyma in liquid minimal medium culture; (B) steam-exploded sugarcane bagasse parenchyma in liquid minimal medium culture following $36 \mathrm{~h}$ incubation with $A$. tamarii BLU37; (C) steam-exploded sugarcane bagasse parenchyma in liquid minimal medium culture following $48 \mathrm{~h}$ incubation with $A$. tamarii BLU37. Bars $=100 \mu \mathrm{m} ; 200 \mathrm{X}$ magnification. 

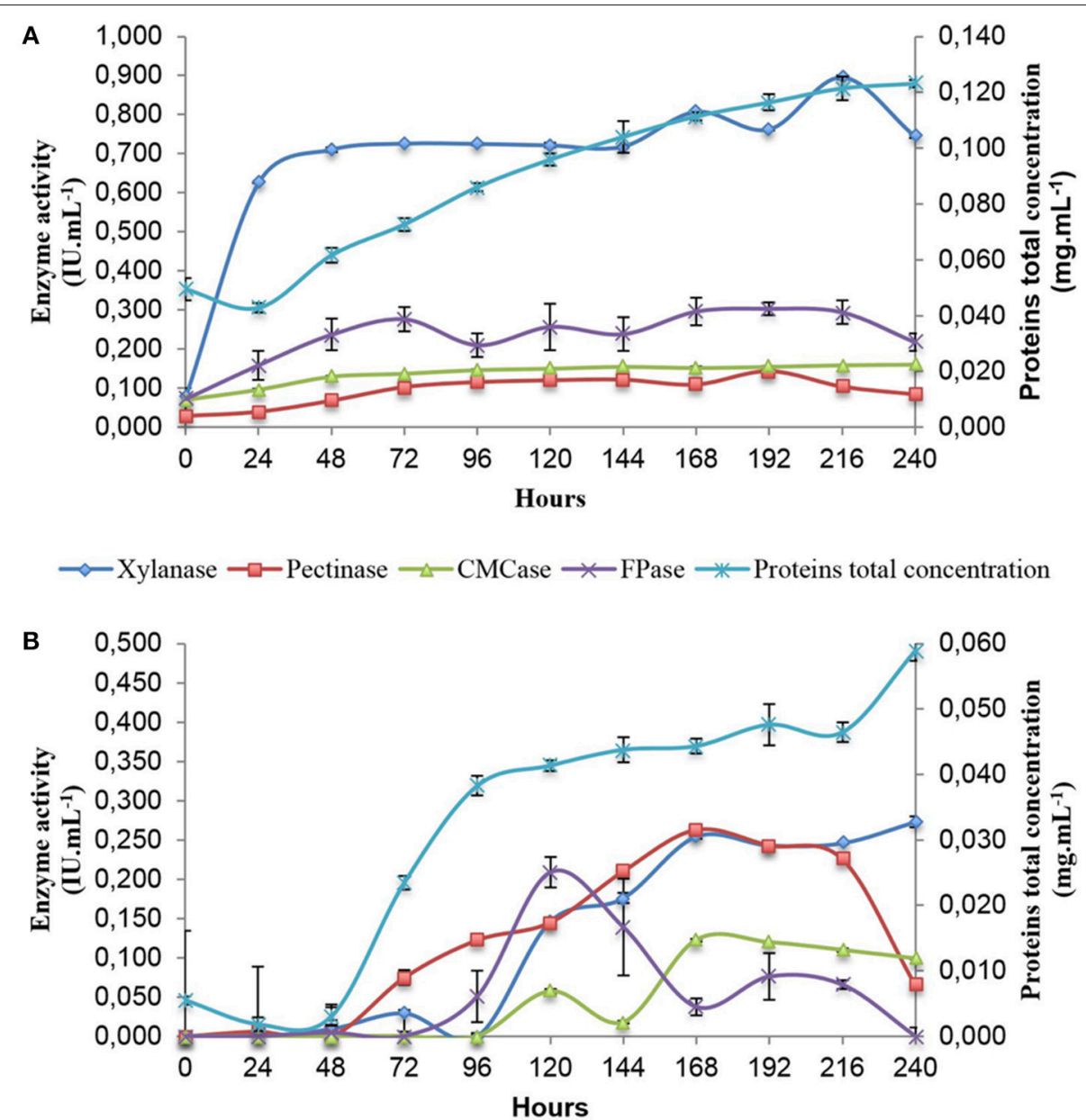

$\multimap$ Xylanase $\rightarrow-$ Pectinase $-\backsim$ CMCase $\leftarrow$ FPase $\rightarrow$ Proteins total concentration

FIGURE 2 | Enzymatic activity profile of A. tamarii BLU37 in response to xylan, pectin, carboxymethylcellulose and filter paper substrates following growth in liquid minimal medium supplemented with sugarcane $(1 \% \mathrm{~W} / \mathrm{V}) \mathbf{( A )}$ or glucose $(1 \% \mathrm{~W} / \mathrm{V}) \mathbf{( B )}$ as carbon source. Activities were determined through a DNS assay at pH 5.0 .

transcriptome of $A$. tamarii BLU37 in response to SB or glucose as carbon source.

\section{Transcriptome of Aspergillus Tamarii BLU37 in Response to Sugarcane Bagasse Sequence Metrics}

Illumina Hiseq2000-sequenced cDNA libraries resulted in a total of $634,255,527$ reads with lengths between 75 and $85 \mathrm{bp}$, totaling $83.82 \mathrm{~Gb}$ of raw data. Illumina quality filtering indicated no information loss on the basis of passfilter data. High quality sequences (Fastq QC>30) averaged $80.34 \%$ after adapter trimming (Supplementary Table 1). The total of paired and unpaired reads mapping to the reference genome $A$. oryzae RIB40 was 94 and $84 \%$, respectively. An indel percentage of approximately $0.002 \%$ was observed in quality filtered sequences, with a low total of chimeric reads, at $0.000949 \%$. All Illumina RNAseq data was deposited at the NCBI Sequence Read Archive
(SRA) database (BioProject ID PRJNA479954, SRA accession: SRP152413).

\section{Gene Expression Modulation}

Sequence data generated from each of the cDNA libraries successfully aligned to over 7120 of the 12074 gene models in the reference $A$. oryzae RIB40 genome. Such homogeneity in characterized genes across cDNA libraries indicates a high quality and coverage of sequenced mRNA.

Analysis of fold change in gene expression was conducted on read counts aligned to each gene model in the reference A. oryzae RIB40 genome. DEGs with significant fold change (at least $\geq 2$-fold and at a probability level of $p \leq 0.01$ ) between treatments were identified through comparison of mapped read counts for genes expressed in cultures grown on SB as carbon source, in contrast read counts following growth on respective glucose controls. Differential gene expression analysis was also conducted in relation to culture 


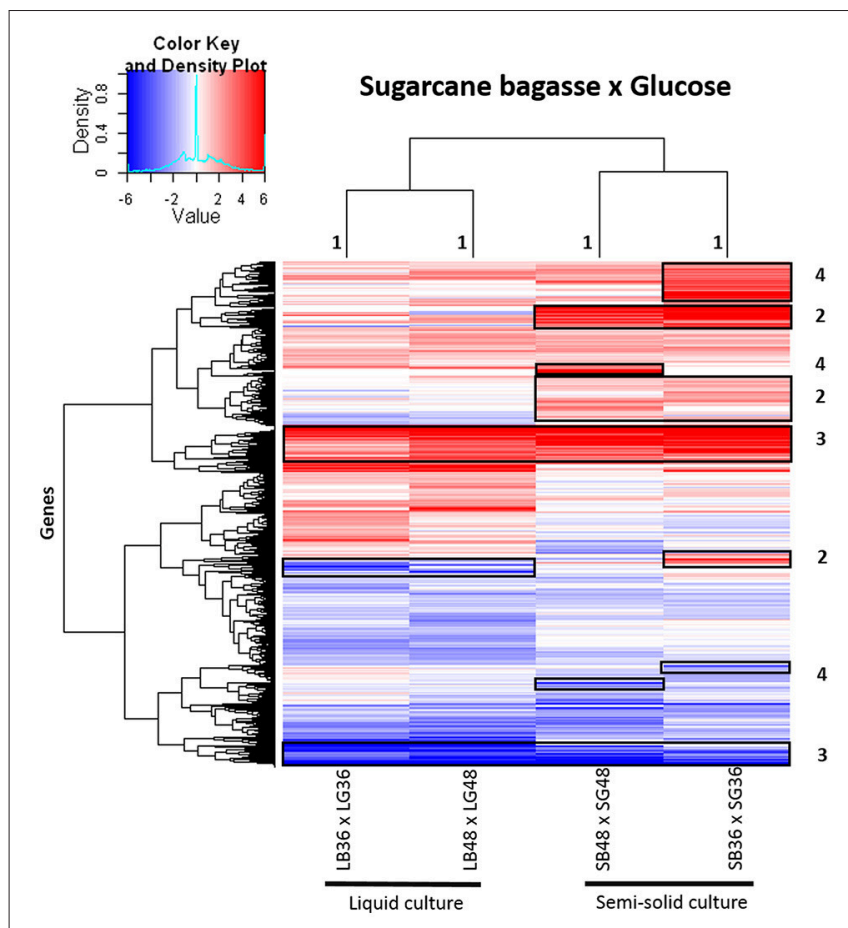

FIGURE 3 | Heatmap of hierarchical clustering of gene transcript modulation patterns observed in A. tamarii BLU37 following growth on SB in comparison to glucose as carbon source. Gene transcripts were compared between growth treatments LB36 and LG36, LB48 and LG48, SB36 and SG36, and SB48 and SG48 (padj < 0.01). All $\log _{2}$ FoldChange values below -6 or above 6 were considered as minimum and maximum values. Categorized groupings of expressed genes one to four are referred to in the main text of the results.

format (liquid or semi-solid) and growth period (36 or $48 \mathrm{~h})$.

A global heatmap representation of gene expression profiles in A. tamarii BLU37 following growth on SB in comparison to glucose revealed considerable modulation of gene expression following growth on this source of plant cell wall polysaccharides (Figure 3). Modulated genes on SB, in comparison to glucose, that grouped exclusively according to culture format (liquid or semi-solid culture), and independent of the growth period, can be observed in Figure 3, region 1. Modulated genes after growth on SB were also identified that grouped according to both culture format and growth period (Figure 3, region 2), according to $\mathrm{SB}$ as carbon source, independent of culture format or growth period (Figure 3, region 3), or exclusively according to growth period (Figure 3, region 4). Comparison of expression levels in the predicted genes identified in each of the treatments, whether in growth media supplemented with SB or glucose, revealed that gene expression in A. tamarii can also be influenced exclusively according to growth period or culture format, regardless of carbon source (Supplementary Figure 1).

Numerous genes were detected with significant expression fold change on SB as sole carbon source in comparison to glucose at an equivalent growth time point. For LB36, a total of 621 DEGs were detected with significant expression up-regulation, plus a total of 919 DEGs showing down-regulation. For LB48, numbers were greater, with 1187 DEGs up-regulated and 1229 down-regulated. The overall number of DEGs observed following growth on semi-solid media was generally lower than observed on liquid media. For SB36, a total of 755 DEGs were significantly up-regulated, with 449 down-regulated. Similarly for SB48, a total of 914 DEGs were detected as up-regulated and 445 as down-regulated.

\section{Gene Ontology Enrichment Analysis of Differentially Expressed Genes}

Differentially expressed genes were analyzed for over- and under-representation according to gene function classification within gene ontology categories (GO) (Figure 4). The majority of annotations for DEGs were classified in biological process subcategories, followed by molecular function and cellular component. Biological process GO terms enriched in DEGs up-regulated following SB hydrolysis included those involved in xylan (GO:0045493), pectin (GO:0045490) and glucan (GO:0009251) catabolic process, with enrichment of up to 4.2 times in all treatments supplemented with SB. Xyloglucan metabolic process (GO:0010411) was the most pronounced of such GO terms, with an enrichment of 8.4 times for the treatment SB48. By contrast, glycolytic process (GO:0006096), glucose catabolic process (GO:0006007), fatty acid (GO:0006633) and ergosterol biosynthetic process (GO:0006696) were abundant terms for down-regulated DEGs following growth in SB-supplemented treatments, indicating that genes classified under these GO terms are more highly expressed in the treatments supplemented with glucose. With regard to molecular function, subcategories cellulase (GO:0008810), galactosidase (GO:0015925), pectate lyase (GO:0030570), alpha-L-arabinofuranosidase (GO:0046556), carboxylic ester hydrolase (GO:0052689) and glucosidase activity (GO:0015926) were all enriched in up-regulated DEGs following growth on SB-supplemented treatments, providing further evidence for $A$. tamarii as a promising fungal species for secretion of cellulases and hemicellulases.

\section{CAZyme-Encoding Genes}

With regard to plant cell wall degradation in SB, global analysis of gene expression following fungal growth in the four treatments LB36, LB48, SB36, and SB48 revealed the presence of a total of 311,314, 337, and 324 expressed CAZyme-encoding genes, respectively, after growth in treatments with this complex carbon source. Differential expression modulation in relation to equivalent treatments with glucose is summarized in Figure 5. A. tamarii BLU37 clearly expressed important genes related to SB degradation, with a total of 209 CAZy-encoding genes with statistically significant differential expression on SB, either in liquid or semi-solid treatments, in comparison to equivalent growth treatments with glucose as carbon source (Table 1; Supplementary Table 2). In terms of those with significant modulation of gene expression, genes encoding $\mathrm{GH}$ family proteins were the most abundant, with a total of 141 DEGs observed, followed by 15 DEGs encoding CEs, 15 DEGs encoding PLs, four DEGs encoding AA proteins and 32 DEGs encoding 


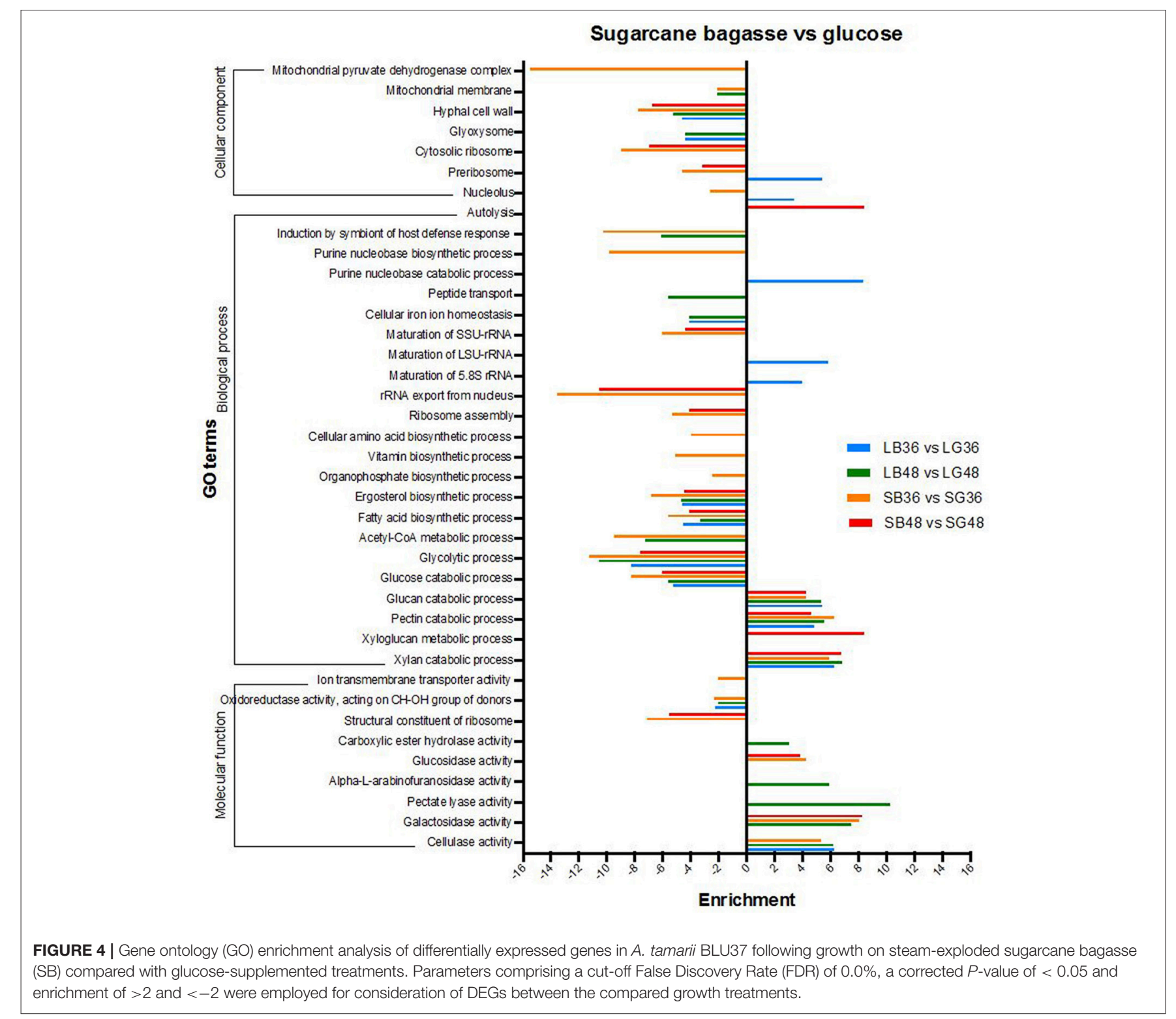

GTs. A Venn representation of total numbers of CAZymeencoding DEGs in treatments LB36, LB48, SB36 and SB48 revealed 50 genes that were common to all four treatments and likely representing those essential in hydrolysis of the complex carbon source SB (Figure 6).

DEGs involved in cellulose depolymerization included $\beta$-1,4-endoglucanases, cellobiohydrolases, $\beta$-glucosidases, and lytic polysaccharide mono-oxygenases (LPMO). Genes with expression modulation of up to 10 -fold were also observed amongst the DEGs, including numerous encoding hemicellulases related to xylan depolymerization such as xylanase, endoxylanase, endo- $\beta-1,4$-xylanase, $\alpha$-Larabinofuranosidase, arabinofuranosidase, and feruloyl esterase. Genes related to pectin depolymerization were also highly expressed, such as for those encoding polygalacturonase, pectinesterase, pectin and pectate lyase. A total of 40 CAZyme-encoding DEGs were exclusive to specific treatments with sugarcane. Interestingly, most were expressed positively in the treatment SB36 and were related to pectin hydrolysis. These included, for example, orthologos for genes encoding a polygalacturonase (AO090009000470), a rhamnogalacturonan hydrolase (AO090102000139), a pectin lyase (AO090010000030), and a $\beta$-glucosidase (AO090701000841).

\section{Differentially Expressed Transcription Factor and Transporter-Encoding Genes}

A total of 80 transcription factor genes were differentially expressed in A. tamarii BLU37 following growth on sugarcane in comparison with equivalent treatments with glucose (padj $<$ 0.01) (Supplementary Table 3). These comprised genes with transcription factor activity domains in families such as Zn2/Cys6 DNA-binding domain, Homeodomain, C2H2 zinc fingers, helix-loop-helix DNA-binding domain, GATA zinc finger and Basic-leucine zipper (bZIP). An ortholog for the 


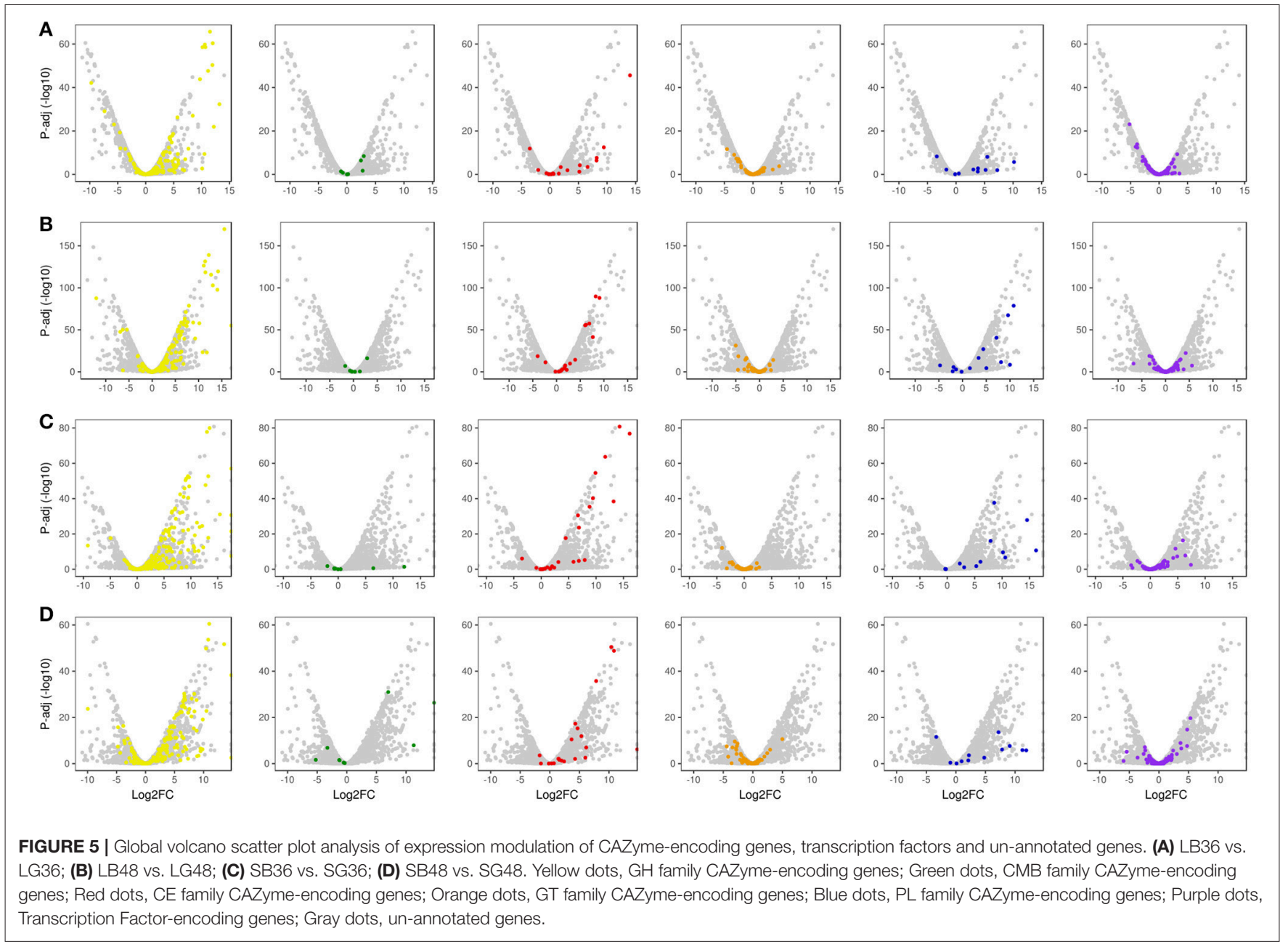

transcription factor gene XlnR (AO090012000267), known to be responsible for activation of genes involved in xylan and cellulose degradation, showed an increased expression of up to 1-fold in LB48 and 1.46-fold in SB36. Additionally, the XlnR gene ortholog AO090003001292, showed increased expression of 2.06-fold in LB48 and 1.75-fold in SB48. Similarly, an ortholog of the ClrA transcription factor gene AO090011000944, which is positively regulated by $\mathrm{XlnR}$, was differentially modulated 2.33-fold in LB36, 2.34-fold in LB48 and 2.07-fold in SB36. Two transcription factors controlling pectinase-encoding genes, namely RhaR (AO090005000121) and AraR (AO090003001292), were also up-regulated, 1.80fold in LB48, 2.60-fold in SB36, 2.05-fold in LB48 and 1.74 in SB48. Interestingly, an ortholog of the BlrA gene (AO090005001041), a DNA binding transcription factor involved in asexual sporulation in fungi, displayed an early up-regulation in the treatments on sugarcane bagasse, with a 1.11-fold increase in expression in LB36 followed by a 0.73 -fold decrease in LB48, together with a 7.40-fold increase in expression in SB36 and subsequent 1.70-fold decrease in gene expression in SB48. Transcription factor genes that are known to act in repression of cellulases and hemicellulases, such as the zincfinger carbon catabolite repressor transcription factor CreA (AO090026000464) (Ruijter and Visser, 1997), together with Ace1 (AO090005001502) and Ace2 (AO090003000678), whilst observed amongst the unigenes identified in the $A$. tamarii transcriptome, were not significantly differentially expressed on sugarcane bagasse in comparison to growth on glucose as carbon source.

A total of 155 transporter genes were differentially expressed across the four treatments on sugarcane, in comparison to glucose (Supplementary Table 4). Highly expressed genes related to sugar transport were, in the majority, those known to be positively regulated by the transcription factor $\mathrm{X} \ln \mathrm{R}$ and coding for Major Facilitator Superfamily (MFS) proteins. Orthologs of the genes AO090003000782, AO090001000069, and AO090003001277 were the most positively differentially expressed of such genes in all treatments on sugarcane, in comparison to glucose. The putative D-xylose transmembrane transporter XtrD (AO090001000069) was also highly expressed on sugarcane bagasse (log2FC 5.02 in LB36, 5.57 in LB48, 7.16 in SB36 and 4.68 in SB48), as was the putative cellobiose transporter 
cdt-2 gene ortholog (AO090003001277), expressed at log2FC levels 6.53 in LB36, 9.10 in LB48, 8.48 in SB36 and 6.07 in SB48.

\section{Validation of RNAseq Analysis by RT-qPCR}

In order to validate Illumina RNAseq-derived gene expression data, a total of 14 highly expressed CAZyme-encoding genes were selected for expression profile analysis by RT-qPCR. These gene orthologs, which are known to be positively regulated by XlnR, comprised cellobiohydrolases (AO090001000348, AO090012000941, AO090038000439), endoxylanases (AO090103000423, AO090120000026, AO090001000111), feruloyl esterase (AO090701000884), pectinesterase (AO090102000010), polygalacturonase (AO090102000011), arabinofuranosidase (AO090103000120), $\quad \beta$-xylosidase (AO090005000986), exoarabinase (AO090011000141), endoglucanase (AO090026000102), and a Lytic Polysaccharide Mono-Oxygenase (LPMO) (AO090023000787). Both RNAseq and RT-qPCR gene expression values are represented in log2FoldChange, showing broad agreement in expression pattern tendencies to up- or down-regulation in each of the four treatment comparisons (Figure 7). Primer sequences for target genes selected for validation via RT-qPCR are available in Supplementary Table 5.

\section{DISCUSSION}

Efficient $2 \mathrm{G}$ bioethanol production systems require the complete hydrolysis of hexose and pentose sugars present in plant biomass. In this study, a global analysis of the transcriptome revealed considerable ligninolytic potential in the ascomycete fungus $A$. tamarii BLU37. With an abundance of expressed CAZyme-encoding genes, data on the transcriptional response to contrasting carbon sources of sugarcane bagasse and glucose both increase understanding of the mechanisms involved in enzyme secretion and efficiency, and serve as a resource for exploitation of genes encoding transcription factors, transporters and enzymes involved in the degradation of plant biomass for engineering of improved microorganisms.

As plant pathogens or saprophytes, many filamentous fungi are efficient in hydrolytic extracellular enzyme secretion for plant biomass depolymerization. A number of species belonging to the genus Aspergillus are efficient in secretion of a large repertoire of glycosyl hydrolases appropriate for industrial application in lignocellulosic biomass degradation (Machida et al., 2005; Duarte et al., 2012; Jaramillo et al., 2013; Pirota et al., 2014). The strain examined in this study was originally isolated from composting cotton textile waste material (Siqueira et al., 2009). Typically, this species is associated with plant biomass degradation as a spoilage fungus, with reports of isolation from food and feed products (Rodrigues et al., 2011; Midorikawa et al., 2014; Martins et al., 2017; Prencipe et al., 2018). Previous studies have also highlighted the potential in this species in depolymerization of xylan, through secretion of $\beta$-1,4-endoxylanases (Gouda and Abdel-Naby, 2002; da Silva et al., 2014). Efficient secretion of such xylanases has also been reported in the strain $A$. tamarii BLU37 (Duarte et al., 2012; Monclaro et al., 2016). Whilst the transcriptome in different Aspergillus species during degradation of plant biomass has been the subject of recent investigation (de Souza et al., 2011; Delmas et al., 2012; Pullan et al., 2014; van Munster et al., 2014; Miao et al., 2015; Borin et al., 2017), despite the clear potential of $A$. tamarii as a xylanolytic species, there has been no investigation, prior to the current study, of the transcriptome of this species during saccharification of plant biomass.

The A. tamarii BLU37 transcriptome in response to SB was mapped to the annotated reference $A$. oryzae RIB40 genome, with the total number of expressed genes detected (7126 genes) similar to that previously observed in A. niger (7359 genes) when grown on this same lignocellulosic substrate as sole carbon source (Borin et al., 2017). Global analysis of gene expression revealed DEGs not only induced or repressed according to culture treatments with SB or C, but also according to semi-solid versus liquid culture (Supplementary Figure 1). Culture format has previously also been reported to influence enzyme secretion in Aspergillus species, with greater protein production in A. oryzae following solid-state fermentation (Wang et al., 2010b). Similarly, in the case of $A$. niger, solid-state fermentation of pretreated sugarcane bagasse was reported to favor endoglucanase and xylanase secretion, with submerged fermentation favoring $\beta$ glucosidase production (Vasconcellos et al., 2015).

Enzymes involved in the degradation of plant cell wall polysaccharides are distributed in different classes of glycosidases based on their primary amino acid sequence and related catalytic modules. Currently, these enzymes are classified as carbohydrate esterases (CEs), polysaccharide lyases (PLs), glycoside hydrolases (GHs), glycosyltransferases (GTs), as enzymes with the auxiliary activities (AAs), and as carbohydratebinding modules (CBMs). As lignocellulose deconstruction requires the activities of a large number of these CAZymes, analysis of DEGs included a comparison of CAZyme-encoding genes. Considering that Aspergillus sp. are able to colonize a variety of plant biomass polysaccharides, and given that sugarcane bagasse has been shown to comprise approximately $35 \%$ cellulose, $24 \%$ hemicellulose and $22 \%$ lignin (Rezende et al., 2011), it was expected that $A$. tamarii BLU37 would secrete many enzymes from different CAZy families when growing on SB as carbon source. The majority of the CAZyme-encoding genes observed amongst DEGs on SB were those encoding proteins classified across $36 \mathrm{GH}$ families. The total of $141 \mathrm{GH}$ family DEGs reflects the similar numbers identified in the genomes of $A$. oryzae, $A$. terreus, $A$. niger and $A$. nidulans, with respective totals of 194, 186, 157, and 172 predicted GH family CAZyme-encoding genes. Greatest numbers of genes with differential expression on SB included those from GH families 3, 5, 31, 43, and 92. CAZyme-encoding DEGs classified in CE families (15 genes) and PL families (15 genes) were also similar in numbers to those observed in the A. oryzae genome, where $14 \mathrm{CE}$ and $20 \mathrm{PL}$ genes have been annotated (Benoit et al., 2015). DEGs encoding GTs were generally less expressed on SB in comparison to glucose, indicating a probable lack of involvement in degradation of this biomass. GTs represent a diverse family of enzymes that function in the cell in many activities relating to structure, storage and signaling. Numerous GTs can transfer sugar residues from an activated sugar donor residue to specific acceptor molecules, 
TABLE 1 | CAZyme-encoding genes with significant increased expression after growth in treatments with steam exploded bagasse, in comparison with glucose.

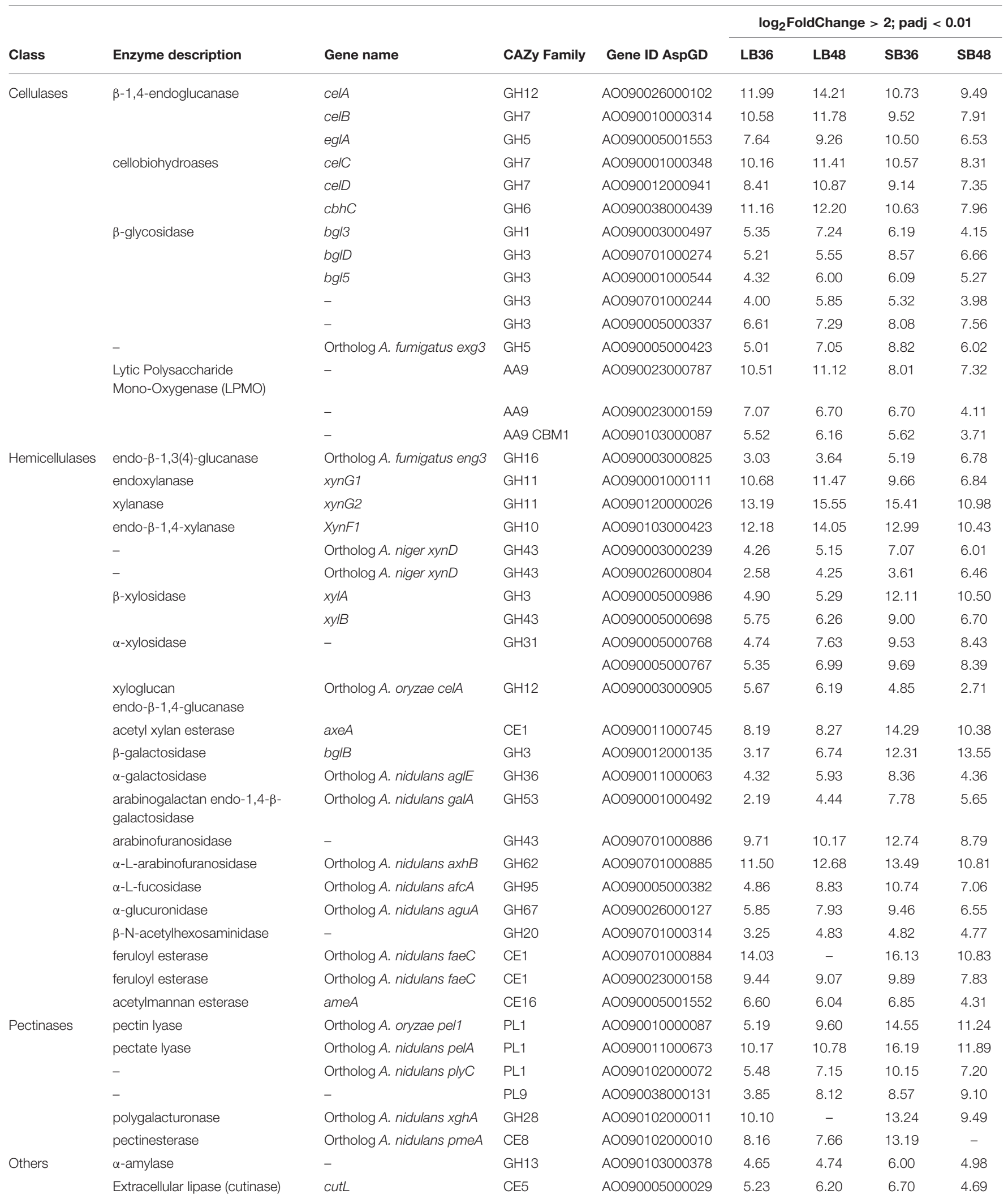




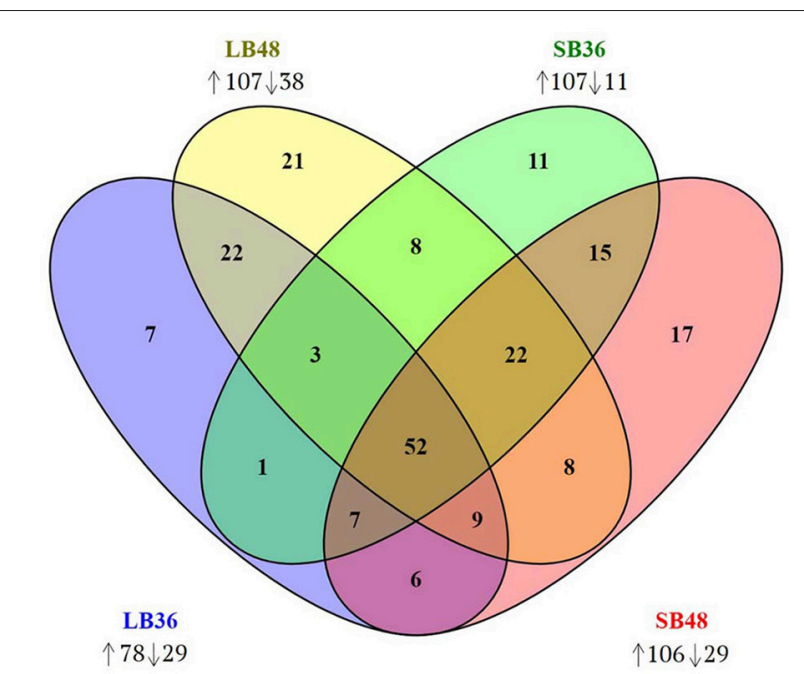

FIGURE 6 | Venn diagram of CAZyme-encoding genes observed in treatments LB36, LB48, SB36, and SB48. Differentially expressed genes were considered significant if relative expression in comparison to equivalent treatments with glucose as carbon source showed at least a 2 -fold change and considering a false discovery rate (FDR)-adjusted $P$-value (padj) at 0.01 . Arrows pointing up or down: CAZyme-encoding genes up-regulated or down-regulated in each treatment.

resulting in the formation of glycosidic bonds. As such, this family of enzymes can enable the biosynthesis of an infinite number of oligosaccharides, polysaccharides and glycoconjugates (Taniguchi et al., 2002; Coutinho et al., 2003). As such, in contrast to sugarcane bagasse, where enzyme activity is involved in the degradation of plant cell wall polysaccharides, an increased expression of GTs on glucose may be expected, likely resulting in the biosynthesis of oligosaccharides and polysaccharides required for fungal metabolism. Such observations have also been reported in A. fumigatus on different lignocellulosic biomass sources (Miao et al., 2015; de Gouvêa et al., 2018), with many such GTs involved in the biosynthesis of fungal cell wall chitins and ergosterol glycosylation (Klutts et al., 2006; Castell-Miller et al., 2016). Additional DEGs likely to be not involved in the plant cell wall degradation included six GH18 putative chitinases, with activity likely associated with cell wall dynamics during fungal growth, as also observed in the ascomycete fungus Malbranchea cinnamomea (Hüttner et al., 2017).

Genes related to cellulose and hemicellulose deconstruction were highly expressed during liquid and semi-solid culture on SB (Supplementary Table 2), including cellobiohydrolases (CBHs) (celC - AO090001000348, celD - AO090012000941 and chbC - AO090038000439), endoglucanases (EGs) (celA - AO090026000102, celB - AO090010000314 and eglA - AO090005001553), and $\beta$-glucosidases (BGLs) (bgl3 - AO090003000497, bglD - AO090701000274 and bgl5 - AO090001000544). Two putative $\beta$-glucosidases (AO090701000244 and AO090005000337) and one putative exoglucanase (AO090005000423) were also observed with high levels of expression during liquid and semi-solid culture. In the case of the CAZy family AA9, classified as a member of the copper-dependent lytic polysaccharide monooxygenases (LPMOs) and responsible for cellulose cleavage through an oxidative reaction, two AA9 genes (AO090023000787 and AO090023000159) and two AA9 genes linked by a carbohydrate-binding module (CBM1) (AO090103000087 and AO090005000531) were observed amongst the highly expressed DEGs on SB, as also reported in A. niger (Borin et al., 2017). Cellulose-binding CBMs are frequently observed amongst fungal enzymes, playing roles in anchoring enzymes to crystalline cellulose (Igarashi et al., 2009), conferring enzyme and substrate specificity and enhancing enzyme activity (Crouch et al., 2016). CBM1s have been estimated to represent over 30\% of CBMs in Ascomycete and Basidiomycetes (Várnai et al., 2014).

Whilst sugarcane bagasse hemicellulose and pectin have structures composed of xylan, galactan and arabinan polymers, many of the highly expressed DEGs from liquid and semisolid cultures grown on sugarcane bagasse were related to xylan saccharification, corroborating enzyme activity data and previous studies on $A$. tamarii. The endoxylanases (xynG1 - AO090001000111, xynF1 - AO090103000423) and xylanase (xynG2 - AO090120000026), for example, were upregulated more than 10-fold in SB. Xylosidases involved in xylooligomer hydrolysis into xylose, such as $\alpha$-xylosidases (AO090005000768 and AO090005000767) and $\beta$-xylosidases (xylA - AO090005000986 and xylB - AO090005000698), also showed high expression levels.

Genes that encode accessory enzymes involved in galactan breakdown, such as $\beta$-galactosidase and $\alpha$-galactosidase (AO090012000135 and AO090011000063), as well as those involved in xylan side chain removal, such as arabinofuranosidases (AO090701000886 and AO090701000885) and feruloyl esterases (AO090701000884 and AO090023000158), were all also highly expressed in liquid and semi-solid SB culture.

Fungi from the genus Aspergillus possess a variety of genes encoding enzymes related to pectin degradation. A. niger possesses over 60 such genes and $A$. oryzae over 90 genes encoding for pectinolytic enzymes (Coutinho et al., 2009; Martens-Uzunova and Schaap, 2009). In our study, we detected numerous pectin-related DEGs with increased expression on SB. Genes with increased expression on semi-solid SB included a number from the PL1 family (AO090010000087, AO090011000673, and AO090102000072), the PL9 family (AO090038000131), pectinase-encoding genes from the GH28 family (exopolygalacturonase - AO090005001400; polygalacturonase - AO090009000470 and AO090138000086; and rhamnogalacturonan hydrolase - AO090102000139), as well as one gene from the PL1 family, a pectin lyase (AO090010000030). In contrast, a number of PL1 family DEGs displayed increased expression exclusively in liquid SB culture, namely AO090012000451, AO090701000321, and AO090010000706. Such data reveal that culture format of this carbon source, in addition to cultivation time, can influence gene expression. Although pectin is less abundant in sugarcane bagasse in comparison to xylan, in terms of chemical composition (de Souza et al., 2013), the presence of PL family members amongst the DEGs also indicates pectin breakdown in SB. Similar increased expression has previously been observed in 

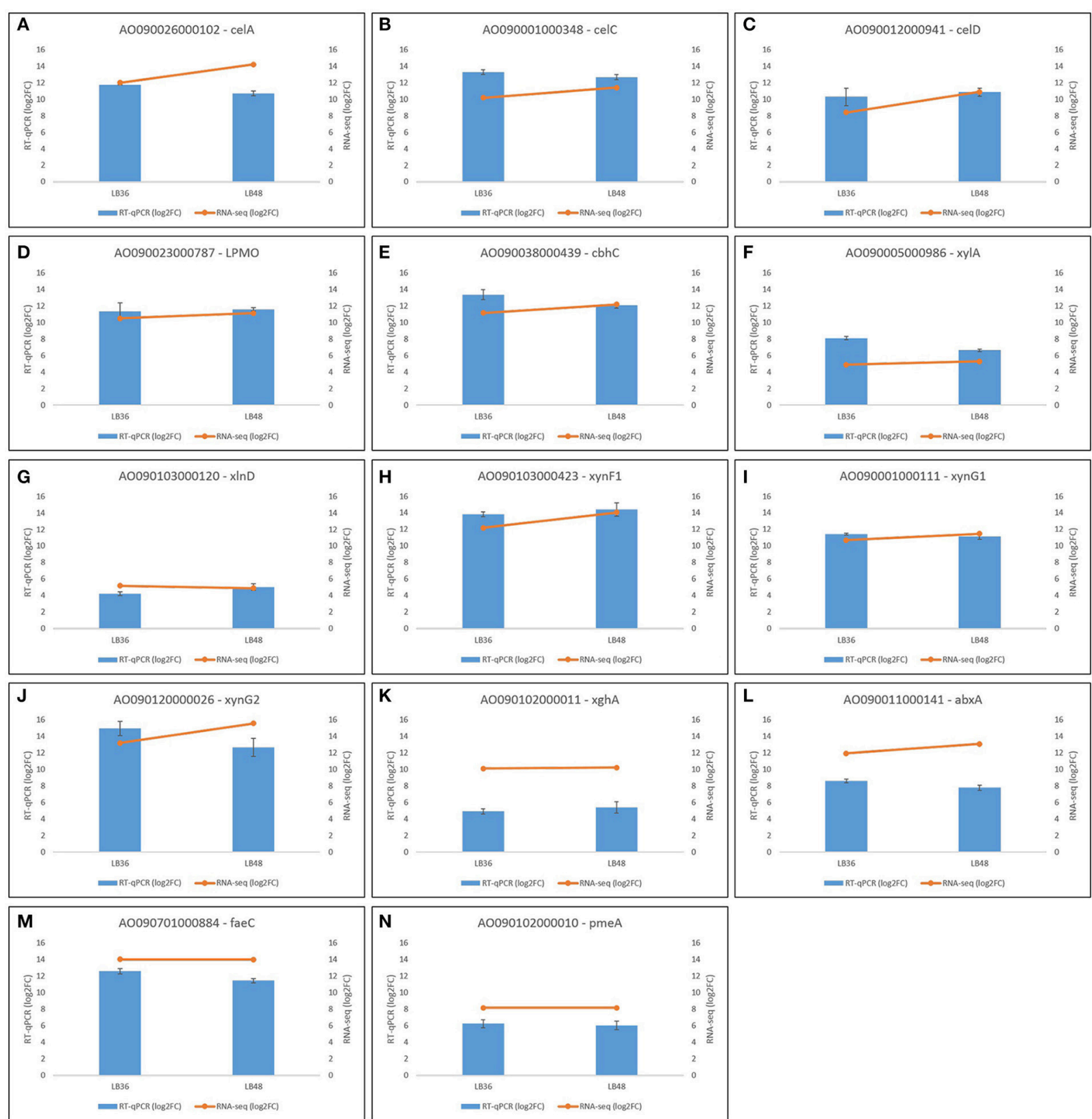

FIGURE 7 | Validation of differential gene expression profiles based on RNAseq through RT-qPCR analysis in selected genes (A-N) in Aspergillus tamarii BLU37. Black bars represent standard error values, which are based on analysis of three biological replicates per treatment and three technical amplification replicates.

PL4 family member genes in A. niger and A. fumigatus grown on SB (Borin et al., 2017; de Gouvêa et al., 2018).

Transcription factors perform major roles in the regulation of gene expression. Our data revealed a total of 80 differentially expressed transcription factor genes, from the families Zn2/Cys6 DNA-binding domain, Homeodomain-like, C2H2 zinc fingers, helix-loop-helix DNA-binding domain, GATA zinc finger and Basic-leucine zipper (bZIP) transcription factor. Amongst the DEGs, a total of 42 transcription factors were identified, from $\mathrm{Zn}$ clusters, a family commonly found across fungal species
(Shelest, 2017). Of these, the transcription factor $\mathrm{X} \ln \mathrm{R}$ is known to play an important role in xylanolytic transcriptional activation in fungi (van Peij et al., 1998), controlling expression of a wide range of genes, including those encoding xylanases and enzymes in the D-xylose metabolic pathway (Hasper et al., 2000; de Groot et al., 2007). This TF is also involved in regulation of expression of genes encoding endocellulases (Gielkens et al., 1999). In the case of Aspergilli specifically, XlnR is known, in the presence of D-xylose, to induce xylanases, $\beta$ xylosidases, cellobiohydrolases, endoglucanases, galactosidases, 
arabinofuranosidases and carbohydrate esterases (Mach-Aigner et al., 2012). In this study, $X \ln R$ was up-regulated according to $\mathrm{SB}$ substrate, as observed previously in $A$. niger in response to SB, over a similar time course (Borin et al., 2017), as well as in A. fumigatus on rice straw (Miao et al., 2015). Up-regulation was also observed in the ClrA gene following growth in LB36 and LB48. Together with $\mathrm{X} \ln R$, this gene is also known to act positively in cellulase production in A. niger (Raulo et al., 2016). Two transcription factors controlling pectinase-encoding genes, namely RhaR and AraR were also up-regulated in LB and SB. The major pectinase-encoding genes in $A$. niger have been shown to be under the control of the transcription factors RhaR, AraR, and GaaR (Kowalczyk et al., 2017), suggesting that the up-regulation of the RhaR and AraR observed in our study, also indicates a role in induction of pectinase-encoding gene expression in A. tamarii, releasing lignin associated with pectin in the sugarcane bagasse cell wall.

Following the breakdown of lignocellulosic biomass into mono- and disaccharide sugars, transport into the cell will involve numerous sugar transporters. Although genome sequence data has revealed that filamentous fungi indeed harbor many genes encoding sugar transporters, relatively few have been functionally validated to date (dos Reis et al., 2016). MFS transporter proteins are known to transport small soluble molecules such as sugars across ion gradients (Pao et al., 1998). Following comparison with all predicted MFS proteins in the annotated reference genome sequences for A. oryzae (508), A. nidulans (357), and A. fumigatus (278) (Ferreira et al., 2005), our data revealed over 150 potential transporter genes differentially expressed in A. tamarii following growth on sugarcane bagasse in comparison to glucose. The relatively large number of transporters identified in the genus Aspergillus, in comparison with $T$. reesei and $N$. crassa, may explain their greater ability to transport small solutes (Miao et al., 2015). Previously, de Souza et al. (2011) characterized seven genes encoding predicted transporters in A. niger, with increased expression in response to sugarcane bagasse and repression in the presence of glucose, suggesting a role in xylose transport. From our data, numerous differentially expressed transporter genes potentially involved in SB degradation were identified. Increased expression of the putative D-xylose transmembrane transporter gene $x \operatorname{tr} D$, for example, likely indicates involvement in transport into the cell of free D-xylose released from xylan following activity of highly expressed xylanases, endoxylanases and xylosidases. In accord with our findings, the $x \operatorname{trD}$ gene from $A$. nidulans, whilst able to accept multiple sugars (xylose, glucose, galactose, and mannose), shows high affinity for xylose, being induced by xylose in an XlnR-dependent manner, and repressed by glucose in a CreA-dependent manner (Colabardini et al., 2014). Similarly, significant increased expression of the $c d t-2$ gene ortholog, a putative cellobiose transporter, was observed across all four treatments with SB as carbon source, likely associated with cellobiose transport into the fungal cell. Given the inability of $S$. cerevisiae to transport sugars other than glucose (Young et al., 2010), the identification of transporters for pentose sugars and cellodextrins in A. tamarii will offer potential in genetic modification of Saccharomyces yeasts, facilitating transport and fermentation of D-xylose.

Whilst there is evidence for conservation of the genomic potential for plant biomass degradation across certain Aspergillus species (Benoit et al., 2015), investigation into gene expression and enzyme secretion has shown considerable variation across species and during cultivation on different carbon sources. This first analysis of the repertoire of CAZyme-, transcription factor- and sugar transporter-encoding genes in A. tamarii modulated in response to $\mathrm{SB}$ increases our understanding of enzymatic saccharification of this lignocellulosic biomass. Transcriptome data serves as a resource for economically viable biorefinary applications, with potential for application in improvement of enzymatic conversion of biomass to value-added products, through genetic improvement of both lignocellulolytic filamentous fungi, as well as yeasts employed in the fermentation of hexose and pentose sugars in hydrolysates in industrial $2 \mathrm{G}$ ethanol production.

\section{DATA AVAILABILITY}

The Illumina RNAseq datasets generated for this study can be found in the NCBI Sequence Read Archive (SRA) database (BioProject ID PRJNA479954, SRA accession: SRP152413).

\section{AUTHOR CONTRIBUTIONS}

$\mathrm{RM}, \mathrm{EN}$, and EF planned the experiments. GM and CC performed the bioassays, enzyme analyses, RNA and cDNA preparation, and sequence data analysis. RT, MC, OS, and PG participated in sequence data analysis and editing of the manuscript. RM conceived the study, participated in bioassays, RNA preparation for cDNA library construction, sequence data analysis, and drafted the manuscript. All authors have contributed to, read and approved the final version of the manuscript.

\section{FUNDING}

This work was partially funded by the Fundação de Amparo à Pesquisa do Distrito Federal (FAPDF) (project 193.000.584/2009). GM and CC were supported by scholarships from CAPES. RM, EN, and EF were supported by fellowships from the CNPq.

\section{ACKNOWLEDGMENTS}

We thank the reviewers for their useful comments on the manuscript.

\section{SUPPLEMENTARY MATERIAL}

The Supplementary Material for this article can be found online at: https://www.frontiersin.org/articles/10.3389/fbioe. 2018.00123/full\#supplementary-material 


\section{REFERENCES}

Altschul, S. F., Gish, W., Miller, W., Myers, E. W., and Lipman, D. J. (1990). Basic local alignment search tool. J. Mol. Biol. 215, 403-410. doi: 10.1016/S0022-2836(05)80360-2

Alvira, P., Tomás-Pejó, E., Ballesteros, M., and Negro, M. J. (2010). Pretreatment technologies for an efficient bioethanol production process based on enzymatic hydrolysis: a review. Bioresour. Technol. 101, 4851-4861. doi: 10.1016/j.biortech.2009.11.093

Amorim, H. V., Lopes, M. L., de Castro Oliveira, J. V., Buckeridge, M. S., and Goldman, G. H. (2011). Scientific challenges of bioethanol production in Brazil. Appl. Microbiol. Biotechnol. 91, 1267-1275. doi: 10.1007/s00253-011-3437-6

Anders, S., Pyl, P. T., and Huber, W. (2015). HTSeq - a Python framework to work with high-throughput sequencing data. Bioinformatics 31:166661. doi: 10.1093/bioinformatics/btu638

Andersen, M. R., Vongsangnak, W., Panagiotou, G., Salazar, M. P., Lehmann, L., and Nielsen, J. (2008). A trispecies Aspergillus microarray: comparative transcriptomics of three Aspergillus species. Proc. Natl. Acad. Sci. U.S.A. 105, 4387-4392. doi: 10.1073/pnas.0709964105

Archer, D. B. (2000). Filamentous fungi as microbial cell factories for food use. Curr. Opin. Biotechnol. 11, 478-483. doi: 10.1016/S0958-1669(00)00129-4

Aronesty, E. (2011). ea-utils: Command-line Tools for Processing Biological Sequencing Data. Available online at: https://github.com/ExpressionAnalysis/ ea-utils

Benoit, I., Culleton, H., Zhou, M., DiFalco, M., Aguilar-Osorio, G., Battaglia, E., et al. (2015). Closely related fungi employ diverse enzymatic strategies to degrade plant biomass. Biotechnol. Biofuels 8:107. doi: 10.1186/s13068-015-0285-0

Borin, G. P., Sanchez, C. C., de Santana, E. S., Zanini, G. K., Dos Santos, R. A. C., de Oliveira Pontes, A., et al. (2017). Comparative transcriptome analysis reveals different strategies for degradation of steam-exploded sugarcane bagasse by Aspergillus niger and Trichoderma reesei. BMC Genomics 18:501. doi: 10.1186/s12864-017-3857-5

Brasileiro, A. C. M., and Carneiro, V. T., De, C. (2015). Manual de Transformação Genética de Plantas, 2nd Edn. Brasília: Embrapa.

Brown, N. A., Ries, L. N., Reis, T. F., Rajendran, R., Corrêa Dos Santos, R. A., Ramage, G., et al. (2016). RNAseq reveals hydrophobins that are involved in the adaptation of Aspergillus nidulans to lignocellulose. Biotechnol. Biofuels 9:145. doi: 10.1186/s13068-016-0558-2

Bustin, S. A., Benes, V., Garson, J. A., Hellemans, J., Huggett, J., Kubista, M., et al. (2009). The MIQE guidelines: minimum information for publication of quantitative real-time PCR experiments. Clin. Chem. 55, 611-622. doi: 10.1373/clinchem.2008.112797

Cantarel, B. L., Coutinho, P. M., Rancurel, C., Bernard, T., Lombard, V., and Henrissat, B. (2009). The carbohydrate-active enzymes database (CAZy): an expert resource for glycogenomics. Nucleic Acids Res. 37, D233-D238. doi: 10.1093/nar/gkn663

Castell-Miller, C. V., Gutierrez-Gonzalez, J. J., Tu, Z. J., Bushley, K. E., Hainaut, M., Henrissat, B., et al. (2016). Genome assembly of the fungus Cochliobolus miyabeanus, and transcriptome analysis during early stages of infection on american wildrice (Zizania palustris L.). PLoS ONE 11:e0154122. doi: 10.1371/journal.pone.0154122

Chundawat, S. P., Beckham, G. T., Himmel, M. E., and Dale, B. E. (2011). Deconstruction of lignocellulosic biomass to fuels and chemicals. Annu. Rev. Chem. Biomol. Eng. 2, 121-145. doi: 10.1146/annurev-chembioeng-061010-114205

Colabardini, A. C.,Ries, L. N., Brown, N. A., Dos Reis, T. F., Savoldi, M., Goldman, M. H., et al. (2014). Functional characterization of a xylose transporter in Aspergillus nidulans. Biotechnol. Biofuels 7:46. doi: 10.1186/1754-6834-7-46

CONAB (2018). Companhia Nacional de Abastecimento (CONAB): Acompanhamento da Safra Brasileira: Cana-De-Açúcar, Primeiro Levantamento, Maio/2018. Brasília: Companhia Nacional de Abastecimento.

Cong, B., Wang, N., Liu, S., Liu, F., Yin, X., and Shen, J. (2017). Isolation, characterization and transcriptome analysis of a novel Antarctic Aspergillus sydowii strain MS-19 as a potential lignocellulosic enzyme source. BMC Microbiol. 17:129. doi: 10.1186/s12866-017-1028-0

Coutinho, P. M., Andersen, M. R., Kolenova, K., Vankuyk, P. A., Benoit, I., Gruben, B. S., et al. (2009). Postgenomic insights into the plant polysaccharide degradation potential of Aspergillus nidulans and comparison to Aspergillus niger and Aspergillus oryzae. Fungal Genet. Biol. 46(Suppl. 1), S161-S169. doi: 10.1016/j.fgb.2008.07.020

Coutinho, P. M., Deleury, E., Davies, G. J., and Henrissat, B. (2003). An evolving hierarchical family classification for glycosyltransferases. J. Mol. Biol. 328, 307-317. doi: 10.1016/S0022-2836(03)00307-3

Couturier, M., Navarro, D., Olivé, C., Chevret, D., Haon, M., Favel, A., et al. (2012). Post-genomic analyses of fungal lignocellulosic biomass degradation reveal the unexpected potential of the plant pathogen Ustilago maydis. BMC Genomics 13:57. doi: 10.1186/1471-2164-13-57

Crouch, L. I., Labourel, A., Walton, P. H., Davies, G. J., and Gilbert, H. J. (2016). The contribution of non-catalytic carbohydrate binding modules to the activity of lytic polysaccharide monooxygenases. J. Biol. Chem. 291, 7439-7449. doi: 10.1074/jbc.M115.702365

da Silva, A. C., Soares de França Queiroz, A. E., Evaristo dos Santos Nascimento, T. C., Rodrigues, C., Gomes, J. E., Souza-Motta, C. M., et al. (2014). Extractive fermentation of xylanase from Aspergillus tamarii URM 4634 in a bioreactor. Appl. Biochem. Biotechnol. 173, 1652-1666. doi: 10.1007/s12010-014-0953-8

de Gouvêa, P. F., Bernardi, A. V., Gerolamo, L. E., de Souza Santos, E., RiañoPachón, D. M., Uyemura, S. A., et al. (2018). Transcriptome and secretome analysis of Aspergillus fumigatus in the presence of sugarcane bagasse. BMC Genomics 19:232. doi: 10.1186/s12864-018-4627-8

de Groot, M. J., van den Dool, C., Wösten, H. A., Levisson, M., VanKuyk, P. A., Ruijter, G. J., et al. (2007). Regulation of pentose catabolic pathway genes of Aspergillus niger. Food Technol. Biotechnol. 45, 134-138.

de Souza, W. R., de Gouvêa, P. F., Savoldi, M., Malavazi, I., de Souza Bernardes, L., a, Goldman, M. H. S., et al. (2011). Transcriptome analysis of Aspergillus niger grown on sugarcane bagasse. Biotechnol. Biofuels 4:40. doi: 10.1186/1754-6834-4-40

de Souza, W. R., Maitan-Alfenas, G. P., de Gouvêa, P. F., Brown, N. A., Savoldi, M., Battaglia, E., et al. (2013). The influence of Aspergillus niger transcription factors AraR and XlnR in the gene expression during growth in d-xylose, 1arabinose and steam-exploded sugarcane bagasse. Fungal Genet. Biol. 60, 29-45. doi: 10.1016/j.fgb.2013.07.007

Delmas, S., Pullan, S. T., Gaddipati, S., Kokolski, M., Malla, S., et al. (2012). Uncovering the genome-wide transcriptional responses of the filamentous fungus Aspergillus niger to lignocellulose using RNA sequencing. PLoS Genet. 8:e1002875. doi: 10.1371/journal.pgen.1002875

dos Reis, T. F., de Lima, P. B., Parachin, N. S., Mingossi, F. B., Oliveira, J. V., Ries, L. N., et al. (2016). Identification and characterization of putative xylose and cellobiose transporters in Aspergillus nidulans. Biotechnol. Biofuels 9:204. doi: 10.1186/s13068-016-0611-1

Duarte, G. C., Moreira, L. R. S., Gómez-Mendoza, D. P., Siqueira, F. G., Batista, L. R., Amaral, L. I. V., et al. (2012). Use of residual biomass from the textile industry as carbon source for production of a low-molecular-weight xylanase from Aspergillus oryzae. Appl. Sci. 2, 754-772. doi: 10.3390/app2040754

El-Gindy, A. A., Saad, R. R., and Fawzi, E. M. (2015). Purification of $\beta$-xylosidase from Aspergillus tamarii using ground oats and a possible application on the fermented hydrolysate by Pichia stipitis. Ann. Microbiol. 65, 965-974. doi: 10.1007/s13213-014-0940-x

Ferreira, M. E., Colombo, A. L., Paulsen, I., Ren, Q., Wortman, J., Huang, J., et al. (2005). The ergosterol biosynthesis pathway, transporter genes, and azole resistance in Aspergillus fumigatus. Med. Mycol. 43(Suppl. 1), S313-S319. doi: 10.1080/13693780400029114

Galagan, J. E., Calvo, S. E., Cuomo, C., Ma, L.-J., Wortman, J. R., Batzoglou, S., et al. (2005). Sequencing of Aspergillus nidulans and comparative analysis with A. fumigatus and A. oryzae. Nature 438, 1105-1115. doi: 10.1038/nature04341

Ghose, T. K. (1987). Measurement of cellulase activities. Pure Appl. Chem. 59, 257-268. doi: 10.1351/pac198759020257

Gielkens, M. M., Dekkers, E., Visser, J., and de Graaff, L. H. (1999). Two cellobiohydrolase encoding genes from Aspergillus niger require $\mathrm{D}$-xylose and the xylanolytic transcriptional activator XlnR for their expression. Appl. Environ. Microbiol. 65, 4340-4345.

Glass, N. L., and Donaldson, G. C. (1995). Development of primer sets designed for use with the PCR to amplify conserved genes from filamentous ascomycetes. Appl. Environ. Microbiol. 61, 1323-1330.

Goldemberg, J. (2007). Ethanol for a sustainable energy future. Science 315, 808-810. doi: 10.1126/science. 1137013 
Goldemberg, J. (2008). The Brazilian biofuels industry. Biotechnol. Biofuels 1:6. doi: 10.1186/1754-6834-1-6

Gouda, M. K., and Abdel-Naby, M. A. (2002). Catalytic properties of the immobilized Aspergillus tamarii xylanase. Microbiol. Res. 157, 275-281. doi: 10.1078/0944-5013-00165

Guerriero, G., Hausman, J.-F., Strauss, J., Ertan, H., and Siddiqui, K. S. (2016). Lignocellulosic biomass: biosynthesis, degradation, and industrial utilization. Eng. Life Sci. 16, 1-16. doi: 10.1002/elsc.201400196

Guillemette, T., van Peij, N., Goosen, T., Lanthaler, K., Robson, G. D., Cees van den Hondel, A. M. J. J., et al. (2007). Genomic analysis of the secretion stress response in the enzyme-producing cell factory Aspergillus niger. BMC Genomics 8:158. doi: 10.1186/1471-2164-8-158

Häkkinen, M., Arvas, M., Oja, M., Aro, N., Penttilä, M., Saloheimo, M., et al. (2012). Re-annotation of the CAZy genes of Trichoderma reesei and transcription in the presence of lignocellulosic substrates. Microb. Cell Fact. 11:134. doi: 10.1186/1475-2859-11-134

Hasper, A. A., Visser, J., and de Graaff, L. H. (2000). The Aspergillus niger transcriptional activator $\mathrm{X} \ln \mathrm{R}$, which is involved in the degradation of the polysaccharides xylan and cellulose, also regulates d-xylose reductase gene expression. Mol. Microbiol. 36, 193-200. doi: 10.1046/j.1365-2958.2000.01843.x

Hong, S. B., Cho, H. S., Shin, H. D., Frisvad, J. C., and Samson, R. A. (2006). Novel neosartorya species isolated from soil in Korea. Int. J. Syst. Evol. Microbiol. 56, 477-486. doi: 10.1099/ijs.0.63980-0

Hüttner, S., Nguyen, T. T., Granchi, Z., Chin-A-Woeng, T., Ahrén, D., Larsbrink, J., et al. (2017). Combined genome and transcriptome sequencing to investigate the plant cell wall degrading enzyme system in the thermophilic fungus Malbranchea cinnamomea. Biotechnol. Biofuels 10:265. doi: 10.1186/s13068-017-0956-0

Igarashi, K., Koivula, A., Wada, M., Kimura, S., Penttil,ä, M., and Samejima, M. (2009). High speed atomic force microscopy visualizes processive movement of Trichoderma reesei cellobiohydrolase I on crystalline cellulose. J. Biol. Chem. 284, 36186-36190. doi: 10.1074/jbc.M109.034611

Jaramillo, P. M. D., Gomes, H. A. R., de Siqueira, F. G., Homem-de-Mello, M., Filho, E. X. F., and Magalhães, P. O. (2013). Liquid-liquid extraction of pectinase produced by Aspergillus oryzae using aqueous two-phase micellar system. Sep. Purif. Technol. 120, 452-457. doi: 10.1016/j.seppur.2013.09.020

Jordan, D. B., Bowman, M. J., Braker, J. D., Dien, B. S., Hector, R. E., Lee, C. C., et al. (2012). Plant cell walls to ethanol. Biochem. J. 442, 241-252. doi: 10.1042/BJ20111922

Jørgensen, T. R., Goosen, T., Hondel, C. A., Ram, A. F., and Iversen, J. J. (2009). Transcriptomic comparison of Aspergillus niger growing on two different sugars reveals coordinated regulation of the secretory pathway. BMC Genomics 10:44. doi: 10.1186/1471-2164-10-44

Klutts, J. S., Yoneda, A., Reilly, M. C., Bose, I., and Doering, T. (2006). Glycosyltransferases and their products: cryptococcal variations on fungal themes. FEMS Yeast Res. 6, 499-512. doi: 10.1111/j.1567-1364.2006.00054.x

Kowalczyk, J. E., Lubbers, R. J. M., Peng, M., Battaglia, E., Visser, J., and de Vries, R. P. (2017). Combinatorial control of gene expression in Aspergillus niger grown on sugar beet pectin. Sci. Rep. 7:12356. doi: 10.1038/s41598-017-12362-y

Lin, Y., and Tanaka, S. (2006). Ethanol fermentation from biomass resources: current state and prospects. Appl. Microbiol. Biotechnol. 69, 627-642. doi: 10.1007/s00253-005-0229-x

Livak, K. J., and Schmittgen, T. D. (2001). Analysis of relative gene expression data using real-time quantitative PCR and the $2(\mathrm{~T})(-$ Delta Delta $\mathrm{C})$ method. Methods 25, 402-408. doi: 10.1006/meth.2001.1262

Mach-Aigner, A. R., Omony, J., Jovanovic, B., Van Boxtel, A. J. B., and De Graaff, L. H. (2012). D-xylose concentration-dependent hydrolase expression profiles and the function of CreA and XlnR in Aspergillus niger. Appl. Environ. Microbiol. 78, 3145-3155. doi: 10.1128/AEM.07772-11

Machida, M., Asai, K., Sano, M., Tanaka, T., Kumagai, T., Terai, G., et al. (2005). Genome sequencing and analysis of Aspergillus oryzae. Nature 438, 1157-1161. doi: 10.1038/nature 04300

Martens-Uzunova, E. S., and Schaap, P. J. (2009). Assessment of the pectin degrading enzyme network of Aspergillus niger by functional genomics. Fungal Genet. Biol. 46(Suppl. 1), S170-S179. doi: 10.1016/j.fgb.2008.07.021

Martins, L. M., Sant'Ana, A. S., Fungaro, M. H., Silva, J. J., Nascimento, M. D., Frisvad, J. C., et al. (2017). The biodiversity of Aspergillus section Flavi and aflatoxins in the Brazilian peanut production chain. Food Res. Int. 94, 101-107. doi: 10.1016/j.foodres.2017.02.006

Mckelvey, S. M., and Murphy, R. A. (2010). Analysis of wide-domain transcriptional regulation in solid-state cultures of Aspergillus oryzae. J. Ind. Microbiol. Biotechnol. 37, 455-469. doi: 10.1007/s10295-010-0691-z

Miao, Y., Dongyang, L., Guangqi, L., Pan, L., Yangchun, X., Qirong, S., et al. (2015). Genome-wide transcriptomic analysis of a superior biomass-degrading strain of A. fumigatus revealed active lignocellulose-degrading genes. BMC Genomics 16:459. doi: 10.1186/s12864-015-1658-2

Midorikawa, G. E., de Sousa, M., de, L., Freitas Silva, O., Dias, J. do, S., et al. (2014). Characterization of Aspergillus species on Brazil nut from the Brazilian Amazonian region and development of a PCR assay for identification at the genus level. BMC Microbiol. 14:138. doi: 10.1186/1471-2180-14-138

Miller, G. L. (1959). Use of dinitrosalicylic acid reagent for determination of reducing sugar. Anal. Chem. 31, 426-428. doi: 10.1021/ac60147a030

Mohanram, S., Amat, D., Choudhary, J., Arora, A., and Nain, L. (2013). Novel perspectives for evolving enzyme cocktails for lignocellulose hydrolysis in biorefineries. Sustain. Chem. Process. 1:15. doi: 10.1186/2043-7129-1-15

Monclaro, A. V., Aquino, E. N., Faria, R. F., Ricart, C. A. O., Freitas, S. M., and Midorikawa, G. E. O., et al. (2016). Characterization of multiple xylanase forms from Aspergillus tamarii resistant to phenolic compounds. Mycosphere 7 , 1554-1567. doi: 10.5943/mycosphere/si/3b/7

Pao, S. S., Paulsen, I. T., and Saier, M. H. Jr. (1998). Major facilitator superfamily. Microbiol. Mol. Biol. Rev. 62, 1-34.

Pel, H. J., de Winde, J. H., Archer, D. B., Dyer, P. S., Hofmann, G., Schaap, P. J., et al. (2007). Genome sequencing and analysis of the versatile cell factory Aspergillus niger CBS 513.88. Nat. Biotechnol. 25, 221-231. doi: 10.1038/nbt1282

Phitsuwan, P., Laohakunjit, N., Kerdchoechuen, O., Kyu, K. L., and Ratanakhanokchai, K. (2013). Present and potential applications of cellulases in agriculture, biotechnology, and bioenergy. Folia Microbiol. 58, 163-176. doi: 10.1007/s12223-012-0184-8

Pirota, R. D. P. B., Delabona, P. S., and Farinas, C. S. (2014). Enzymatic hydrolysis of sugarcane bagasse using enzyme extract and whole solid-state fermentation medium of two newly isolated strains of Aspergillus oryzae. Chem. Eng. Trans. 38, 259-264. doi: 10.3303/CET1438044

Pitt, J. I., and Hocking, A. D. (2009). Fungi and Food Spoilage, $3 r d$ Edn. New York, NY: Springer. doi: 10.1007/978-0-387-92207-2

Prencipe, S., Siciliano, I., Contessa, C., Botta, R., Garibaldi, A., Gullino, M. L., et al. (2018). Characterization of Aspergillus section flavi isolated from fresh chestnuts and along the chestnut flour process. Food Microbiol. 69, 159-169. doi: 10.1016/j.fm.2017.08.004

Prüfer, K., Muetzel, B., Do, H. H., Weiss, G., Khaitovich, P., Rahm, E., et al. (2007). FUNC: a package for detecting significant associations between gene sets and ontological annotations. BMC Bioinformatics 8:41. doi: 10.1186/1471-2105-8-41

Pullan, S. T., Daly, P., Delmas, S., Ibbett, R., Kokolski, M., Neiteler, A., et al. (2014). RNAsequencing reveals the complexities of the transcriptional response to lignocellulosic biofuel substrates in Aspergillus niger. Fungal Biol. Biotechnol. 1, 1-14. doi: 10.1186/s40694-014-0003-x

Raeder, U., and Broda, P. (1985). Rapid preparation of DNA from filamentous fungi. Lett. Appl. Microbiol. 1, 17-20. doi: 10.1111/j.1472-765X.1985.tb01479.x

Ragauskas, A. J., Williams, C. K., Davidson, B. H., Britovsek, G., Cairney, J., Eckert, C. A., et al. (2006). The path forward for biofuels and biomaterials. Science 311, 484-489. doi: 10.1126/science.1114736

Raulo, R., Kokolski, M., and Archer, D. B. (2016). The roles of the zinc finger transcription factors $\mathrm{X} \ln \mathrm{R}, \mathrm{Clr} \mathrm{A}$ and $\mathrm{ClrB}$ in the breakdown of lignocellulose by Aspergillus niger. AMB Express 6:5. doi: 10.1186/s13568-016-0177-0

Rezende, C. A., de Lima, M. A., Maziero, P., de Azevedo, E. R., Garcia, W., and Polikarpov, I. (2011). Chemical and morphological characterization of sugarcane bagasse submitted to a delignification process for enhanced enzymatic digestibility. Biotechnol. Biofuels 4:54. doi: 10.1186/1754-6834-4-54

Rodrigues, P., Santos, C., Venâncio, A., and Lima, N. (2011). Species identification of Aspergillus section flavi isolates from Portuguese almonds using phenotypic, including MALDI-TOF ICMS, and molecular approaches. J. Appl. Microbiol. 111, 877-892. doi: 10.1111/j.1365-2672.2011.05116.x

Ruijter, G. J., and Visser, J. (1997). Carbon repression in Aspergilli. FEMS Microbiol. Lett. 151, 103-114. doi: 10.1111/j.1574-6968.1997.tb12557.x 
Salazar, M., Vongsangnak, W., Panagiotou, G., Andersen, M. R., and Nielsen, J. (2009). Uncovering transcriptional regulation of glycerol metabolism in Aspergilli through genome-wide gene expression data analysis. Mol. Genet. Genomics 282, 571-586. doi: 10.1007/s00438-009-0486-y

Shelest, E. (2017). Transcription factors in fungi: tfome dynamics, three major families, and dual-specificity TFs. Front. Genet. 8:53. doi: 10.3389/fgene.2017.00053

Silva, C. G., Vaz, R. P., and Filho, E. X. F. (2017). Bringing plant cell wall-degrading enzymes into the lignocellulosic biorefinery concept. Biofuels Bioprod. Biorefin. 12, 277-289. doi: 10.1002/bbb.1832

Sims, R. E., Mabee, W., Saddler, J. N., and Taylor, M. (2010). An overview of second generation biofuel technologies. Bioresour. Technol. 101, 1570-1580. doi: 10.1016/j.biortech.2009.11.046

Singhania, R. R. (2011). "Production of celluloytic enzymes for the hydrolysis of lignocellulosic biomass," in Biofuels: Alternative Feedstocks and Conversion Processes, ed R. R. Singhania (Amsterdam: Elsevier), 101-22.

Siqueira, F. G., Siqueira, E. G., Jaramillo, P. M. D., Silveira, M. H. L., Andreaus, J., Couto, F. A., et al. (2009). The potential of agro-industrial residues for production of holocellulase from filamentous fungi. Int. Biodeterior. Biodegrad. 64, 20-26. doi: 10.1016/j.ibiod.2009.10.002

Tan, H.-T., Corbin, K. R., and Fincher, G. B. (2016). Emerging technologies for the production of renewable liquid transport fuels from biomass sources enriched in plant cell walls. Front. Plant Sci. 7:1854. doi: 10.3389/fpls.2016.01854

Taniguchi, N., Honke, K., and Fukuda, M. (2002). Handbook of Glycosyltransferase and Related Genes. Tokyo: Springer.

Trapnell, C., Pachter, L., and Salzberg, S. L. (2009). TopHat: discovering splice junctions with RNA-Seq. Bioinformatics 25, 1105-1111. doi: 10.1093/bioinformatics/btp120

Trapnell, C., Williams, B. A., Pertea, G., Mortazavi, A., Kwan, G., Van Baren, M. J., et al. (2010). Transcript assembly and quantification by RNA-Seq reveals unannotated transcripts and isoform switching during cell differentiation. Nat. Biotechnol. 28, 511-515. doi: 10.1038/nbt.1621

Van Den Brink, J., and De Vries, R. P. (2011). Fungal enzyme sets for plant polysaccharide degradation. Appl. Microbiol. Biotechnol. 91, 1477-1492. doi: 10.1007/s00253-011-3473-2

van Munster, J. M., Daly, P., Delmas, S., Pullan, S. T., Blythe, M. J., Malla, S., et al. (2014). The role of carbon starvation in the induction of enzymes that degrade plant-derived carbohydrates in Aspergillus niger. Fungal Genet. Biol. 72, 34-47. doi: 10.1016/j.fgb.2014.04.006 van Peij, N. N., Visser, J., and de Graaff, L. H. (1998). Isolation and analysis of xlnR, encoding a transcriptional activator co-ordinating xylanolytic expression in Aspergillus niger. Mol. Microbiol. 27, 131-142. doi: 10.1046/j.1365-2958.1998.00 666.x

Várnai, A., Mäkelä, M. R., Djajadi, D. T., Rahikainen, J., Hatakka, A., and Viikari, L. (2014). Carbohydrate-binding modules of fungal cellulases: occurrence in nature, function, and relevance in industrial biomass conversion. Adv. Appl. Microbiol. 88, 103-165. doi: 10.1016/B978-0-12-800260-5.00 004-8

Vasconcellos, V. M., Tardioli, P. W., Giordano, R. L. C., and Farinas, C. S. (2015). Production efficiency versus thermostability of (hemi)cellulolytic enzymatic cocktails from different cultivation systems. Process Biochem. 50, 1701-1709. doi: 10.1016/j.procbio.2015.07.011

Wang, B., Guo, G., Wang, C., Lin, Y., Wang, X., Zhao, M., et al. (2010b). Survey of the transcriptome of Aspergillus oryzae via massively parallel mRNA sequencing. Nucleic Acids Res. 38, 5075-5087. doi: 10.1093/nar/gkq256

Wang, L., Feng, Z., Wang, X., Wang, X., and Zhang, X. (2010a). DEGseq: an $\mathrm{R}$ package for identifying differentially expressed genes from RNAseq data. Bioinformatics 26, 136-138. doi: 10.1093/bioinformatics/ btp612

White, T. J., Bruns, T., Lee, S., and Taylor, J. (1990). “Amplification and direct sequencing of fungal ribosomal RNA genes for phylogenetics," in PCR Protocols: a Guide to Methods and Applications, eds M. A. Innis, D. H. Gelfand, J. J. Sninsky, T. J. White (London: Academic Press), 282-287.

Young, E., Lee, S.-M., and Alper, H. (2010). Optimising pentose utilization in yeast: the need for novel tools and approaches. Biotechnol. Biofuels 3:24. doi: 10.1186/1754-6834-3-24

Conflict of Interest Statement: The authors declare that the research was conducted in the absence of any commercial or financial relationships that could be construed as a potential conflict of interest.

Copyright (c) 2018 Midorikawa, Correa, Noronha, Filho, Togawa, Costa, Silva-Junior, Grynberg and Miller. This is an open-access article distributed under the terms of the Creative Commons Attribution License (CC BY). The use, distribution or reproduction in other forums is permitted, provided the original author(s) and the copyright owner(s) are credited and that the original publication in this journal is cited, in accordance with accepted academic practice. No use, distribution or reproduction is permitted which does not comply with these terms. 